\title{
A nova política monetária: uma análise do regime de metas de inflação no Brasil ${ }^{1}$
}

\author{
Philip Arestis ${ }^{2}$ \\ Luiz Fernando de Paula ${ }^{3}$ \\ Fernando Ferrari-Filho ${ }^{4}$
}

\section{Resumo}

Este artigo analisa, teórica e empiricamente, a "nova" política monetária, entendida, essencialmente, como o que se convencionou chamar regime de metas de inflação. Apesar de o presente artigo examinar o referido regime no âmbito dos países emergentes, o foco será centrado no caso brasileiro e na operacionalização da política monetária por parte do Banco Central desde 1999. O artigo inicia discutindo os fundamentos do regime de metas de inflação e, em seguida, examina a experiência das metas de inflação no Brasil. A experiência brasileira é comparada com a de outros países similares. $\mathrm{O}$ artigo conclui sugerindo que, embora o regime de metas de inflação possa obter o impacto pretendido, qual seja, reduzir e estabilizar o nível de preços, os países que não adotam regimes de metas de inflação também vivenciaram experiências similares de estabilização de preços. Ademais, a experiência brasileira com o regime de metas de inflação tem mostrado que a taxa de crescimento da economia é relativamente baixa e a inflação ainda é ligeiramente elevada.

Palavras-chave: Regime de metas de inflação; Países emergentes; Economia brasileira.

\section{Abstract \\ Assessing the inflation targeting regime in Brazil}

This paper is concerned with 'new' monetary policy, essentially what has come to be known as inflation targeting (IT). While the paper aims to examine this policy in the case of emerging countries, the focus is on Brazil and the application of this monetary policy framework in the case of this country since 1999. The paper begins by discussing the theoretical foundations and operational aspects of IT, before it turns to an examination of the experience of IT in Brazil. The Brazilian experience is compared and contrasted with that of other similar countries. The paper concludes by suggesting that although IT have had the intended impact, non-IT countries have also had a similar experience. Furthermore, the Brazilian experience with IT has been one of low growth and relatively high inflation.

Key words: Inflation targeting countries; Non-inflation targeting countries; Emerging country experience; Brazilian economy.

JEL E42, E52.

(1) Trabalho recebido em outubro de 2006 e aprovado em dezembro de 2007. Os autores gostariam de agradecer a Fábio Barcelos, pela imprescindível ajuda na coleta e preparação dos dados para os países emergentes, em especial para o Brasil; a Lilian Furquim, que forneceu relevantes informações para a elaboração da Figura 5; a Elena Schuck, bolsista de iniciação científica da Fapergs, pela tradução do artigo do original em inglês (revista pelos autores); e, finalmente, a dois pareceristas anônimos, pelos comentários e sugestões. Os erros remanescentes do artigo são de responsabilidade dos autores.

(2) Professor Titular da Universidade de Cambridge, Reino Unido. E-mail: pa267@ cam.ac.uk.

(3) Professor Adjunto da Universidade do Estado do Rio de Janeiro (FCE/UERJ)/Pesquisador do CNPq, Rio de Janeiro, RJ, Brasil. E-mail: luizfpaula@terra.com.br.

(4) Professor Titular da Universidade Federal do Rio Grande do Sul (UFRGS)/Pesquisador do CNPq, Porto Alegre, RS, Brasil. E-mail: ferrari@ufrgs.br. 


\section{Introdução ${ }^{5}$}

O propósito deste artigo é analisar o regime de metas de inflação - IT (sigla em inglês relativa a "inflation targeting") - para os países emergentes, em especial o caso brasileiro. O regime de IT é um "novo" regime de política monetária que tem sido adotado por um número significativo de países (ver, por exemplo, Bernanke; Mishkin, 1997, e Sterne, 2002). O Brasil adotou o referido regime a partir de junho de 1999. Por mais que o enfoque do presente artigo seja direcionado para o Brasil, será examinada, também, a experiência de outros países que tenham adotado o regime de IT, pois o propósito é comparar e evidenciar a extensão do sucesso dessa "nova" política monetária. Ademais, será comparada a experiência brasileira com o regime de IT com a experiência de outros países que não tenham adotado o regime de IT. Assim sendo, uma vez realizada a análise comparativa, questionar-se-á se há substanciais diferenças em relação ao controle do processo inflacionário quando se adota (ou não) o regime de IT.

O artigo está dividido em seis seções, incluindo esta Introdução. A Seção 1 explora os principais aspectos operacionais pertinentes à estrutura do regime de IT. Em seguida, na Seção 2, é feita uma breve análise sobre a lógica das recentes políticas de estabilização implementadas na América Latina, especialmente no Brasil. Tal análise possibilita demonstrar como os países, e o Brasil em especial, implementaram as estratégias de IT. A Seção 3 concentra-se na experiência brasileira com o regime de IT. A Seção 4 enfoca a natureza da inflação brasileira e compara a experiência brasileira sob o regime de IT com a de outros países emergentes "similares". Para efeito de análise comparativa, considerar-se-á um grupo de países emergentes tanto da América Latina quanto da Ásia e do Leste Europeu. A seção final resume e conclui o artigo.

\section{Aspectos operacionais do regime de IT}

Existem diversos aspectos operacionais que sustentam o regime de IT. Na presente seção, serão examinados os principais elementos operacionais do regime de IT.

\subsection{Principais elementos do modus operandi do regime de IT $^{6}$}

Existem, pelo menos, seis elementos que balizam o modus operandi do regime de IT:

(5) Este artigo é uma versão modificada e ampliada de Arestis et al. (2007a).

(6) Arestis e Sawyer (2003) apresentam uma detalhada análise sobre a estrutura teórica do regime de IT. 
(i) O regime de IT é uma estrutura de política monetária em que os anúncios públicos das metas oficiais de inflação, ou bandas de variação, estão comprometidos com o reconhecimento de que a estabilidade de preços - inflação estável e baixa - é o objetivo essencial de longo prazo da política monetária (King, 2002). Eventualmente, as metas de estabilidade de preços podem ser acompanhadas pelo objetivo de estabilidade do produto, desde que a estabilidade dos preços não seja violada. Metas numéricas explícitas para a inflação são publicadas periodicamente, bem como há um espaço de tempo para se alcançar a meta de inflação preestabelecida. Essa estrutura de política monetária melhora a comunicação entre o público, os empresários e os mercados em geral, e os policy makers, provendo disciplina, responsabilidade, transparência e flexibilidade da política monetária. O foco é a estabilidade de preços, obtida a partir de três objetivos: credibilidade (a estrutura do regime de metas deve sinalizar confiança para os agentes econômicos); flexibilidade (a estrutura operacional deve permitir à política monetária uma ação ex ante de forma a evitar choques não antecipados); e legitimidade (a operacionalização do regime de IT deve contar com suportes público e parlamentar). De fato, a credibilidade é considerada predominante na conduta da política monetária a fim de evitar problemas associados com inconsistência intertemporal (Barro e Gordon, 1983). Argumenta-se que essa política, em situações de ocorrência de falta de credibilidade por inconsistência intertemporal, não é ótima e tampouco viável (Kydland; Prescott, 1977; Calvo, 1978; Barro; Gordon, 1983).

(ii) Uma das funções do regime de IT é "amarrar" (lock-in) os ganhos obtidos com o controle da inflação. Bernanke et al. (1999, p. 288) são explícitos nesse ponto, quando argumentam que "one of the main benefits of inflation targets is that they may help to 'lock in' earlier disinflationary gains particularly in the face of one-time inflationary shocks". Por sua vez, Johnson (2003), contudo, depara-se com resultados controversos a respeito desse argumento. Ele compara previsões atuais com previsões feitas por profissionais durante cinco meses consecutivos dos 12 meses imediatamente após o anúncio da meta de inflação. $\mathrm{O}$ estudo isola o efeito do anúncio de metas de inflação no nível da inflação esperada para os casos da Austrália, do Canadá, da Nova Zelândia, da Suécia e do Reino Unido. As conclusões são de que, por um lado, uma redução imediata, mas pequena, na inflação esperada é observada na Nova Zelândia e na Suécia, ao passo que na Austrália e no Canadá a redução imediata na inflação esperada é significativa. Por outro, para o Reino Unido, o anúncio das metas de inflação não apresentou impactos significativos.

(iii) No regime de IT, a política monetária é o principal instrumento da política macroeconômica. A política físcal não é vista como um instrumento macroeconômico eficiente, pois "monetary policy moves first and dominates, 
forcing fiscal policy to align with monetary policy" (Mishkin, 2000, p. 4). A política monetária é um instrumento flexível para se alcançar o objetivo de estabilidade de preços e constitui-se na responsável principal da inflação, tanto que, no longo prazo, o índice de inflação é a única variável macroeconômica que pode ser afetada pela política monetária. Política monetária não afeta a atividade econômica, como, por exemplo, níveis de emprego e produto, no longo prazo.

(iv) A política monetária não deve ser operacionalizada por políticos, mas, sim, por especialistas na forma de um banco central "independente". Em geral, os políticos são tentados a operacionalizar a política monetária para ganhos de curto prazo (manter baixo o desemprego) em detrimento das perdas de longo prazo (alta inflação), o que se convencionou chamar problemas de inconsistência intertemporal (Kydland; Prescott, 1977). Um banco central "independente" possui maior credibilidade nos mercados financeiros e é mais comprometido do que os políticos para manter a inflação sob controle. Há, também, as questões da independência de instrumentos, quando os instrumentos de política monetária estão sob o controle do banco central independente, e da independência das metas, quando o banco central independente estipula as metas da política monetária (Debelle; Fischer, 1994; Fischer, 1994). Argumenta-se que a independência dos instrumentos é preferível para isolar o banco central independente das políticas de inconsistência intertemporal. No entanto, em termos dos objetivos da política monetária, acredita-se que um banco central independente deve ser o "objetivo dependente", de modo que suas preferências de longo prazo coincidam com as preferências da sociedade, ou seja, governos eleitos (Bernanke et al., 1999).

(v) Mecanismos de abertura, transparência e responsabilidade devem estar presentes nas formulações de política monetária. A abertura e a transparência, quando presentes na conduta da política monetária, melhoram a credibilidade. Bancos centrais que adotam regime de IT publicam relatórios de inflação que podem incluir não só a trajetória da inflação, mas, também, da produção e de outras variáveis macroeconômicas, juntamente com uma avaliação das condições econômicas. Há, também, alguns mecanismos de responsabilidade: se a meta de inflação não for alcançada, passos específicos são adotados pelo banco central, tais como a publicação de um relatório explicativo ou a submissão de uma carta ao governo explicando as razões pelas quais não houve o cumprimento das metas preestabelecidas e que medidas serão implementadas para que, no futuro, as referidas metas sejam atingidas. Além disso, a transparência reduz as incertezas sobre as preferências do banco central, cuja função é reduzir as taxas esperadas da inflação.

(vi) No caso de economias abertas que tenham adotado o regime de IT, as considerações sobre taxas de câmbio são de importância crucial, e ressalta-se esse aspecto para os países emergentes, particularmente o Brasil, como será visto em 
seguida. Essas considerações transmitem certos efeitos nas mudanças dos instrumentos de política monetária. Em face do mecanismo transmissor da taxa de câmbio sobre a política monetária, flutuações excessivas nas taxas de juros podem produzir variações significativas no produto por meio da indução de mudanças abruptas nas taxas de câmbio. Isso sugere metas de taxa de câmbio. Contudo, a experiência em países emergentes que implementaram metas de taxa de câmbio e, por conseguinte, sofreram crises monetário-cambiais por causa de suas políticas econômicas pouco críveis é relevante para o argumento. A adoção do regime de IT, em contraste, pode conduzir à estabilidade da moeda, mas desde que seja sinalizado um claro comprometimento com a estabilidade de preços em um sistema de taxa de câmbio flutuante. Isso, naturalmente, não significa dizer que o monitoramento da evolução da taxa de câmbio não deva ser observado. De fato, é desejável considerá-lo nas decisões de escolha dos instrumentos de política monetária. Acredita-se que tal abordagem pode evitar a flutuação da taxa de câmbio, indo ao encontro dos objetivos da estabilidade financeira e de preços (Bernanke; Gertler, 1999).

\subsection{Aspectos operacionais adicionais}

Em termos da estrutura operacional do regime de IT, há vários aspectos a serem considerados. Para começar, há o estabelecimento das metas de inflação; isto é, o ajuste de uma meta pontual ou faixa e a escolha do período de tempo durante o qual a meta deve ser alcançada. É importante notar que o horizonte da meta (sobre o qual o banco central deve atingir a sua meta de inflação) não pode ser mais curto do que o horizonte de controle (sobre o qual a política monetária deve afetar a variável da meta). É claro que escolher uma faixa, em vez de um ponto para as metas de inflação, proporciona uma maior flexibilidade, não só para a estabilidade do produto, mas também para acomodar grandes movimentos na taxa de câmbio nominal; essa é uma questão particularmente emblemática no caso dos países emergentes, e do Brasil, especialmente. Nos casos em que uma faixa é escolhida, há a questão da resposta simétrica/assimétrica para a meta central. O comportamento simétrico apresenta uma preocupação equivalente tanto para inflação quanto para deflação. Tal abordagem reduz a probabilidade da queda da produção e da deflação e, também, indica que o banco central preocupa-se com as flutuações do produto; isso ajuda a manter o apoio à sua independência. Uma abordagem assimétrica para as metas de inflação pode ser vantajosa quando os altos índices de inflação ameaçam a credibilidade.

$\mathrm{O}$ regime de IT também requer o estabelecimento de um modelo ou de uma metodologia que proporcione informações sobre a inflação futura; uma questão que remete à necessidade de previsão da inflação. Há, ademais, uma questão-chave, qual seja: como medir a inflação? Um ponto relevante nesse contexto é se o índice de preços escolhido deve refletir os preços dos bens e 
serviços para o consumo atual ou para os consumos atual e futuro. No último caso, a construção de tal índice de preço é inviável. Logo, há o problema dos movimentos de curto prazo nos preços - geralmente errôneos e "ruidosos" - o que sugere que o índice de preços (de longo prazo) deve ser ajustado ou o núcleo dele deve ser utilizado. Esse índice pode excluir do índice geral de preços alguns itens, tais como preços de alimentos e de energia, choques cambiais, impostos indiretos e/ou preços regulados, na hipótese de que ocorram mudanças resultantes de choques autocorretivos e temporários que contenham pouca informação sobre os movimentos de preços no longo prazo. Esses efeitos, no entanto, podem conter efeitos secundários e duradouros. Por exemplo, um aumento nos impostos indiretos que cause a elevação da inflação temporariamente pode arrefecer a demanda agregada e, por conseguinte, reduzir os preços no longo prazo, implicando uma importante perda de informação sobre o desenvolvimento de preços futuros.

Há ainda a questão do trade-off entre a redução do desvio da inflação da meta e a prevenção de um alto grau de variação do produto. Isso é particularmente pertinente no caso dos choques de abastecimento que fazem a inflação ultrapassar a meta e estão associados, ao mesmo tempo, a menores índices de produção. Diante dessas circunstâncias, as Autoridades Monetárias enfrentam um sério dilema: quanto mais rápida for a variação da produção, menor será o período em que a inflação real estará acima da meta. Porém, quanto mais rápida for a desinflação, maior será a variação potencial do produto. As preferências políticas, bem como a magnitude dos choques de abastecimento, são determinantes importantes nesse trade-off. Nesse contexto, faz-se necessária a flexibilidade, que, no entanto, pode conflitar com a credibilidade, caso os agentes econômicos a interpretem como sendo uma relutância do banco central para deflacionar a economia. Existe, então, um outro dilema, qual seja entre credibilidade e flexibilidade (Garfinkel; Oh, 1993).

Essa discussão destaca um outro importante aspecto operacional que se relaciona à questão das leis monetárias. Os bancos centrais devem, de uma forma ou de outra, sempre seguir as regras de Taylor (Taylor, 1993). Na sua formulação original, essa lei monetária desenvolveu a formulação ad hoc como apresentada na equação abaixo:

(1) $R_{t}=R R^{*}+p^{T}+d_{1} Y_{t}+d_{2}\left(p_{t-1}-p^{T}\right)$,

em que: $\mathrm{R}$ são as taxas de juros usadas para propósitos de controle monetário, $\mathrm{p}^{\mathrm{T}}$ é a inflação desejada na formulação original de Taylor (1993) (na linguagem atual é a meta de inflação estabelecida pelo banco central), $\mathrm{Y}^{\mathrm{g}}$ é o hiato do produto (ou seja, a diferença entre o produto efetivo e o produto potencial) e p é a inflação real. Equações como a (1) são as chamadas regras de Taylor, pois Taylor (1993) 
mostrou que uma simples equação desta forma, com $\mathrm{d}_{1}=0,5$ e $\mathrm{d}_{2}=1,5$, captura, de modo surpreendentemente satisfatório, o comportamento da taxa dos fundos federais dos Estados Unidos e da política monetária do Federal Reserve System (Fed). Dessa maneira, a taxa nominal de juros é aumentada mais do que proporcionalmente a qualquer aumento de inflação. Essa reação política garante que os juros reais são utilizados de forma a reduzir a inflação. Dada a inflação, as taxas reais de juros também sofrem um aumento devido às mudanças positivas no hiato do produto. As regras de Taylor, assim sendo, requerem uma política monetária que aja automaticamente de acordo com a inflação e a produção. Essas regras têm sido criticadas (por exemplo, Svensson, 2004) devido à possibilidade de indeterminação real: se o aumento das taxas nominais de juros em resposta ao aumento da inflação esperada não é suficiente, então a taxa de juros real cai, aumentando a demanda, falhando, assim, em controlar a inflação. Mutatis mutandis, um aumento excessivo na taxa nominal de juros em resposta a um aumento na inflação esperada causaria indeterminação. Todavia, a indeterminação pode ser evitada caso as Autoridades Monetárias respondam de forma agressiva, isto é, com um coeficiente acima da unidade para a inflação esperada, mas não muito acima dela. Esse resultado foi demonstrado no caso de economias fechadas (Clarida; Galí; Gertler, 2000), bem como no caso de pequenas economias abertas (De Fiore; Liu, 2002).

\section{A experiência brasileira: da âncora cambial ao regime de IT}

As políticas de estabilização implementadas na América Latina em geral foram baseadas em alguma forma de âncora nominal, mais especificamente a cambial, em reformas estruturais e institucionais, tais como previdenciária, fiscal e patrimonial, e nas liberalizações das contas comercial e de capitais do balanço de pagamentos. A experiência com as políticas de estabilização mostrou que, embora esses países tenham sido bem-sucedidos ao eliminar uma história de inflação crônica e elevada, as apreciações das moedas domésticas em relação às principais moedas de conversibilidade internacional acabaram causando desequilíbrios expressivos nos balanços de pagamentos. Para restaurar os equilíbrios dos balanços de pagamentos, a solução encontrada pelas Autoridades Monetárias foi a elevação da taxa de juros a fim de atrair "poupança externa". A necessidade de manter os juros elevados para induzir a entrada de capital externo, por sua vez, aumentou a dívida interna pública (visto que as Autoridades Monetárias tiveram que esterilizar a entrada dos referidos capitais), o que acabou deteriorando o resultado fiscal. Nesse sentido, na falta de confidence building e em um contexto de economia globalizada, em que os capitais financeiros e produtivos têm plena mobilidade, o êxito da política de estabilização doméstica gerou um processo endógeno de deterioração dos "fundamentos" macroeconômicos. Como resultado, os países latino-americanos tornaram-se vulneráveis a ataques especulativos às 
suas moedas domésticas, condicionando-os, dessa forma, a crises monetáriocambiais (Kregel, 1999). As crises cambiais no México (1994-1995), no Brasil (1998-1999 e 2002) e na Argentina (2001-2002) são significativos exemplos desse processo dinâmico.

As crises monetário-cambiais latino-americanas dos anos 1990 fizeram com que as Autoridades Monetárias passassem a rever a lógica das políticas de estabilização adotadas em seus países, visto que se, por um lado, a ancoragem cambial estabilizava a dinâmica inflacionária, por outro, ela passou a ser uma das protagonistas das profundas crises cambiais. Assim sendo, algumas Autoridades Monetárias implementaram âncoras nominais alternativas capazes de assegurar a continuidade do processo de estabilização da inflação, sem, todavia, gerar desequilíbrios crônicos de balanço de pagamentos. Como, na ocasião, diversos países desenvolvidos, bem como o Chile, desde 1990, vinham adotando o regime de IT, tal regime acabou tornando-se uma referência monetária alternativa para os países da América Latina, principalmente porque, conforme uma das condições requeridas pelo referido regime, as regras de rigidez monetária exigem uma taxa de câmbio flutuante, imprescindível para equilibrar o setor externo. Dessa maneira, o regime de IT foi adotado pelo México em 1999, pela Colômbia em 1999, pelo Brasil em 1999 e pelo Peru em 2002.

O processo de estabilização econômica brasileira e as suas conseqüências sobre as variáveis macroeconômicas (inflação, contas externas, produto, etc.) nos anos 1990 não foram muito diferentes do que foi descrito acima. O Plano Real seguiu a mesma lógica dos programas de estabilização implementados em grande parte da América Latina, qual seja, em um contexto de abertura da economia e de reformas liberalizantes, a taxa de câmbio passou a ser o preço-âncora e a taxa de juros foi utilizada para propiciar a entrada de capitais externos de curto prazo, visando, com isso, ao equilíbrio do balanço de pagamentos. ${ }^{7}$ Como o volume do fluxo de capitais era muitas vezes superior ao volume necessário para o equilíbrio do balanço de pagamentos, a acumulação de reservas internacionais acabou contribuindo para uma forte apreciação da taxa de câmbio no início do Plano Real (quando se adotou inicialmente um regime de câmbio "assimétrico"), o que colaborou para o recrudescimento dos déficits na balança comercial. O Brasil, em

(7) O Plano Real diferenciou-se do Plano de Convertibilidade da Argentina pela adoção de uma taxa de câmbio âncora mais flexível. No lançamento do programa brasileiro, em julho de 1994, o compromisso do governo era manter a paridade um para um do real com o dólar. Entretanto, a relação entre variações na base monetária e as variações nas reservas internacionais não foi declarada explicitamente, permitindo uma discricionariedade na administração do câmbio, deixando-se o câmbio flutuar inicialmente para baixo, no que ficou conhecido como "banda assimétrica". Após a crise mexicana, a política cambial foi revisada e, no contexto de uma taxa de câmbio à la crawling-peg, a taxa nominal passou a submeter-se à desvalorização gradual. No início de 1999, entretanto, depois de seis meses de pressão especulativa, o real desvalorizou-se e, alguns dias depois, o governo brasileiro adotou a taxa de câmbio flutuante. Ferrari-Filho e Paula (2003) fornecem uma análise abrangente da origem e do desenvolvimento do Plano Real. 
função dos déficits em conta corrente (mais de 4\% do PIB em 1998) e da dependência de capitais externos de curto prazo, passou a conviver com situações de fragilidade externa que, em face do contágio das crises mexicana, do Sudeste Asiático e russa, acabaram ocasionando recorrentes ataques especulativos ao real, ao longo do período 1995-1998. As conseqüências dos referidos ataques especulativos foram duas: por um lado, as reservas cambiais se contraíam; e, por outro, as Autoridades Monetárias eram obrigadas a elevar, ainda mais, a taxa de juros para induzir a entrada de capitais. No final de 1998 e início de 1999, todavia, as Autoridades Monetárias não conseguiram manter a estrutura da política de estabilização implementada com o Plano Real, visto que a crise cambial brasileira era profunda. Assim sendo, o Brasil foi forçado a abandonar o regime de taxa de câmbio à la crawling-peg, responsável pela estabilidade de preços, e passou a adotar o regime de câmbio flutuante. Como consequiência, a taxa de câmbio desvalorizou-se consideravelmente, produzindo, dessa forma, um efeito passthrough para os preços domésticos, gerando pressões altistas de inflação.

Diante desse quadro, as Autoridades Monetárias, receosas da possibilidade de haver uma explosão inflacionária, implementaram, em junho de 1999, o regime de IT, objetivando, assim, manter a inflação sob controle. Ao mesmo tempo, o Banco Central do Brasil (BCB) elevou a taxa de juros de curto prazo para acomodar o choque da desvalorização cambial. Como resultado, ocorreu uma ligeira valorização da taxa de câmbio e a inflação, apesar de sua elevação no início de 1999 , terminou o ano abaixo de $10 \%$.

\section{A experiência brasileira com o regime de $\mathbf{I T}^{8}$}

\subsection{A dimensão institucional}

A política monetária brasileira do regime de IT é baseada no modelo britânico de IT. O Conselho Monetário Nacional (CMN) ${ }^{9}$ estabelece as metas de inflação, que são propostas pelo Ministro da Fazenda. O Comitê de Política Monetária (Copom) ${ }^{10}$ do BCB tem de atingir o alvo da meta de inflação através do uso das taxas de juros de curto prazo. Assim sendo, o BCB trabalha com uma equação à la regra de Taylor e segue sua função reação. A equação relevante é $^{11}$ :

(8) Para uma descrição e análise do regime de metas de inflação no Brasil, ver também Barbosa-Filho (2007).

(9) O CMN tem três membros: o Ministro da Fazenda, o Ministro de Planejamento e o presidente do BCB. Além de ser responsável pela definição das metas de inflação, o CMN também é responsável pela aprovação das principais normas referentes à política monetária, à taxa de câmbio e à regulação do sistema financeiro.

(10) O Copom foi criado em 20 de junho de 1996, ficando encarregado de estabelecer a posição da política monetária e da taxa de juros de curto prazo. Ele é composto pelo quadro de diretores do BCB.

(11) Adaptado de Minella et al. (2003, p. 11). 
(2) $\mathrm{R}_{\mathrm{t}}=\alpha_{1} \mathrm{p}_{\mathrm{t}-1}+\left(1-\alpha_{1}\right)\left[\alpha_{0}+\alpha_{2}\left(\mathrm{E}_{\mathrm{t}} \mathrm{P}_{\mathrm{t}+\mathrm{j}}-\mathrm{P}^{*} \mathrm{t}+\mathrm{j}\right)\right]+\alpha_{3} \mathrm{Yg}_{\mathrm{t}-1}+\alpha_{4} \Delta \mathrm{e}_{\mathrm{t}-1}$,

em que: $\mathrm{R}_{\mathrm{t}}$ representa a taxa Selic ("Sistema Especial de Liquidação e Custódia"), isto é, as taxas de juros estabelecidas pelo COPOM; $\mathrm{E}_{\mathrm{t}} \mathrm{P}_{\mathrm{t}+\mathrm{j}}$ é a expectativa da inflação; $\mathrm{P}^{*}{ }_{\mathrm{t}+\mathrm{j}}$ é a meta de inflação ${ }^{12}$; Yg é o hiato do produto (que se obtém pela diferença entre as séries reais e as séries "filtradas" HP); e $\Delta \mathrm{e}_{\mathrm{t}-1}$ é a variação da taxa de câmbio nominal.

O regime brasileiro de IT estabelece metas de inflação com duração de um ano para o ano corrente e os dois próximos anos. A meta de inflação é baseada em um índice cheio, isto é, o Índice Nacional de Preços ao Consumidor Amplo (IPCA). ${ }^{13}$ Certo grau de flexibilidade é introduzido através da definição de um intervalo de tolerância que tem variado de 2,0 a 2,5 pontos percentuais acima ou abaixo da meta central. A outra razão para a introdução dessa flexibilidade é que ela auxilia o BCB a alcançar as metas de inflação no contexto dos choques internos e externos, aos quais a economia brasileira estava exposta.

A meta de inflação é realizada com êxito quando a variação anual do índice inflacionário estiver dentro dos limites estabelecidos. Se a inflação ultrapassar a meta estabelecida pelo $\mathrm{CMN}$, o presidente do $\mathrm{BCB}$ deve escrever uma carta de conteúdo público ao Ministro da Fazenda explicando as razões pelo fracasso no alcance da meta, bem como deve explicitar todas as medidas propostas para recuperar a meta e o tempo em que essas medidas deverão surtir efeito. A meta da taxa de juros estabelecida pelo Copom é a meta para a taxa de juros da Selic, a taxa de juros de empréstimos interbancários overnight. A meta da Selic é fixada em cada reunião do Copom e, em princípio, deve ser mantida inalterada até a próxima reunião. O presidente do Copom, todavia, tem o direito de alterar as metas da Selic nos períodos entre as reuniões regulares do Copom. Isso somente é possível caso o Copom tenha sinalizado um viés de alta ou de baixa ao fixar o valor da Selic em suas reuniões regulares, sendo que o viés refere-se ao afrouxamento ou aperto da política monetária. O Copom então autoriza o presidente do $\mathrm{BCB}$ a alterar a meta da taxa de juros na direção do viés no período entre as suas reuniões. Oito dias após cada reunião, o Copom emite as Atas no site do BCB e na imprensa. As Atas fornecem um sumário das discussões e decisões do Copom. Ao final de cada trimestre (janeiro/fevereiro/março, abril/maio/junho,

(12) A fim de determinar uma única medida para o desvio da inflação da meta, o BCB usa uma média ponderada entre o desvio esperado do ano atual e o desvio esperado do próximo ano da meta, na qual os pesos são inversamente proporcionais ao número de meses restantes no ano.

(13) O IPCA, calculado pelo IBGE, representa uma amostra de famílias que têm renda de até 40 salários mínimos. A amostra coberta tem uma base geográfica ampla que inclui famílias residentes nas maiores cidades do Brasil. 
julho/agosto/setembro e outubro/novembro/dezembro), o Copom publica o Relatório de Inflação do BCB, que fornece informações detalhadas sobre as condições econômicas, assim como as previsões de inflação do Copom. O objetivo do referido Relatório é informar ao público e ao mercado sobre as metas e a implementação da política monetária.

\subsection{A operacionalização do regime de IT}

A Tabela 1 mostra a inflação efetiva e as metas de inflação para os anos de 1999 a 2005. De 1999 (quando o regime de IT foi introduzido) ${ }^{14}$ até 2002, os intervalos de tolerância variaram 2 pontos percentuais em relação à meta central; em 2003, 2004 e 2005 os intervalos aumentaram para 2,5 pontos percentuais. Em 1999 e 2000, as taxas de inflação foram, respectivamente, 8,94\% e 5,97\% para metas de $8,0 \%$ e $6,0 \%$. Portanto, considerando os intervalos de tolerâncias, as taxas de inflação ficaram dentro do previsível e tolerável. Entretanto, em 2001 e 2002, diversos choques domésticos e externos - tais como a crise energética no Brasil, os efeitos de 11 de setembro de 2001, a crise argentina e a crise de confiança com as eleições presidenciais de 2002 - atingiram a economia brasileira, tendo efeitos significativos sobre a inflação. De fato, a taxa de inflação chegou a 7,7\% em 2001, 1,7\% acima do limite máximo da meta, e elevou-se para 12,5\% em 2002, mais de 5 pontos percentuais acima do limite máximo. De acordo com Minella et al. (2003, p. 6-8), a principal responsável pelo não-cumprimento das metas foi a taxa de câmbio, que aumentou 20,3\% e 53,5\%, em 2001 e 2002, respectivamente. Como resultado, em 2001, 38\% da taxa de inflação podem ser explicados pela depreciação cambial, enquanto, em 2002, a contribuição da variação cambial ficou em $46 \%{ }^{15}$ Em 2003, a taxa de inflação foi de 9,3\%, acima, portanto, da meta ajustada de 8,5\%. ${ }^{16}$ A elevada inflação em 2003 ocorreu, em grande parte, pelo efeito inércia da elevada inflação de 2002, apesar da manutenção da política econômica conservadora de altas taxas de juros implementadas no início do governo Lula da Silva. ${ }^{17}$ Em 2004, o IPCA ficou em

(14) Para maiores informações sobre o histórico macroeconômico que levou à mudança para o regime de IT no Brasil, ver Bogdanki et al. (2000).

(15) Os cálculos de Minella et al. (2003) são baseados no modelo estrutural do BCB e na informação referente aos mecanismos de ajuste de preços administrados.

(16) A Resolução do CMN n. 2.972, de 27 de junho de 2002, alterou a meta de inflação para o ano de 2003 (posteriormente, o BCB estabeleceu para 2003 uma meta ajustada com um limite máximo de 8,5\%), enquanto a Resolução do CMN n. 3.108, de 25 de junho de 2003, alterou a meta de inflação para o ano de 2004. As metas foram aumentadas para 4,0\% em 2003 e 5,5\% em 2004, enquanto as metas originais eram 3,25\% e $3,75 \%$, respectivamente.

(17) Arestis et al. (2007b) fornecem uma análise ampla da política econômica durante o primeiro governo do Presidente Lula da Silva. 
$7,6 \%$, apenas $0,4 \%$ abaixo do limite máximo da meta inflacionária $(8,0 \%)$. A alta dos preços administrados (principalmente gasolina, planos de saúde e tarifas de telefone fixo e de eletricidade) no mesmo ano atingiu 10,2\%, representando $29 \%$ da mudança no IPCA, ou o equivalente a 2,04\% de 10,2\%. Em 2005, a taxa de inflação arrefeceu-se para 5,69\%, ficando dentro dos limites de tolerância estabelecidos pelo $\mathrm{CMN}$ naquele ano. Os fatores que tiveram influência na redução da taxa de crescimento dos preços (principalmente os preços livres de mercado) em 2005 foram, dentre outros, a expansão da oferta de produtos agrícolas (arroz, alimentos perecíveis e grãos de soja) e, principalmente, a valorização cambial.

Tabela 1

Centro, intervalo da meta de inflação e inflação efetiva - 1999-2005

\begin{tabular}{l|c|c|c}
\hline Ano & Centro da Meta & Intervalo da Meta & $\begin{array}{c}\text { Inflação Efetiva } \\
\text { (variação do IPCA) }\end{array}$ \\
\hline 1999 & $8,0 \%$ & 6 a $10 \%$ & $8,94 \%$ \\
\hline 2000 & $6,0 \%$ & 4 a $8 \%$ & $5,97 \%$ \\
\hline 2001 & $4,0 \%$ & 2 a $6 \%$ & $7,67 \%$ \\
\hline 2002 & $3,5 \%$ & 1,5 a $5,5 \%$ & $12,53 \%$ \\
\hline 2003 & $4,0 \%$ & 1,5 a $6,5 \%$ a & $9,30 \%$ \\
\hline 2004 & $5,5 \%$ & 3 a $8 \%$ b & $7,60 \%$ \\
\hline 2005 & $4,5 \%$ & 2 a $7 \%$ & $5,69 \%$ \\
\hline
\end{tabular}

Notas: (a) A meta do ano era inicialmente 3,25\% (+/- 2\%). Depois ela foi alterada para 3,5\% (com intervalo de tolerância de $+/-2 \%$ ); posteriormente o BCB decidiu mudar a meta para $4,0 \%$ com intervalo de tolerância de $2,5 \%$. (b) A meta de inflação do ano era inicialmente $3,75 \%(+/-2,5 \%)$; depois ela foi alterada para 5,5\% e mantido o intervalo de tolerância de +/$2,5 \%$.

Fonte: BCB.

Examinando mais detalhadamente a Tabela 1, é notável que, durante o período de 1999 a 2005, as metas de inflação estiveram dentro dos limites estabelecidos em três dos sete anos iniciais de operacionalização dessa estratégia de política monetária. As metas não foram atingidas em 2001, 2002 e 2003 (apesar de a meta ter sido aumentada de 3,75\% para 8,5\%), sendo que, em 2002, por uma margem substancial. Em uma ocasião diferente (2004), a meta só foi alcançada após esta ter sido elevada em meados de 2003 (ver NR 16). Conclui-se, assim, que o regime de IT no Brasil é passível de crítica no que diz respeito à eficiência da política monetária para atingir o seu objetivo, ou seja, manter a inflação dentro das metas preestabelecidas. Para corroborar tal conclusão, é necessária uma análise comparativa da performance brasileira sob o regime de IT com a de outros países emergentes tanto da América Latina quanto de outros continentes, que adotaram (ou não) o regime de IT. A Seção 4 centra as atenções nessa questão. 


\section{Análise comparativa da experiência brasileira com o regime de IT com a de outros países "similares"}

\subsection{A performance da inflação e do PIB em países emergentes}

A análise realizada nesta seção toma como ponto de partida as Tabelas 2, 3 e 4, que contêm dados pertinentes à inflação e ao PIB (média, desvio-padrão e coeficiente de variação) de um grupo de países emergentes que adotou o regime de IT e de um grupo que não adotou o referido regime. ${ }^{18}$ Dois grupos de países emergentes são analisados: os maiores países latino-americanos e alguns outros países emergentes. Na Tabela 2, períodos muito longos de alta inflação (inflação acima de $50 \%$ ao ano) não foram incluídos nos dados, como, por exemplo, no caso do Brasil antes de 1995 e no caso de Israel antes de $1986 .{ }^{19}$ A análise dos desviospadrão e dos coeficientes de variação pode ser, por vezes, enganosa, como por exemplo, no caso da China, onde o desvio-padrão da alta inflação ocorre devido a um declínio abrupto da taxa de inflação. Apesar disso, esse país tem apresentado índices muito baixos de inflação desde o fim dos anos 1990. É por essa razão que, na Figura 7, 8 e 9 (Anexo) analisamos os dados de inflação de todos os países da amostra, separando os países que adotaram o regime de IT daqueles que não o $\operatorname{adotaram}^{20}$. Esses dados são muito importantes para a análise, uma vez que eles sinalizam a tendência de inflação em cada país.

As Tabelas 2, 3 e 4 mostram claramente que a queda da inflação é uma tendência geral recente nos países emergentes, tenham eles adotado (ou não) o regime de IT (ver, também, as Figuras 7, 8 e 9 - Anexo). Apesar de a taxa de inflação ter declinado em todos os países emergentes que adotaram o regime de IT, na maioria deles o coeficiente de variação aumentou (Tabela 2). Por outro lado, é perceptível, também, que os países que não adotaram o regime de IT experimentaram melhoras substanciais em seus indicadores econômicos (Tabela 3 e Figura 9 - Anexo). De fato, alguns países que não adotaram o regime de IT, tais como China, Índia e Malásia, obtiveram uma taxa de inflação anual abaixo de 4\% nos últimos anos. Para esses países, a estabilidade da taxa nominal de câmbio teve um papel importante para a estabilidade dos preços. Logo, países que adotaram

(18) Para a maioria dos países que não adotaram o regime de IT, nós utilizamos dados estatísticos de 1993 a 2005. Visto que a Turquia adotou o referido regime muito recentemente, em 2006, nós a incluímos como um país pertencente ao grupo de não IT.

(19) A razão para excluir os períodos de alta inflação é que durante tais períodos a taxa de inflação é muitíssimo elevada e após a estabilização (em geral alicerçada em algum tipo de âncora cambial) ela é muito baixa quando comparada com o período anterior, o que acaba produzindo distorções na série temporal dos dados sobre inflação. Tal fato dificultaria uma análise comparativa entre os períodos anteriores e posteriores à adoção do regime de IT que constam na Tabela 2. Para a Tabela 3, entretanto, nós não excluímos quaisquer dados, desde que os mesmos estivessem disponíveis.

(20) Uma vez mais, nós excluímos os períodos de alta inflação das Figuras 7, 8 e 9 - Anexo, pois sua inclusão nesses períodos causaria uma grande distorção dos dados. 
(ou não) o regime de IT experimentaram, recentemente, uma redução inflacionária bastante semelhante. ${ }^{21}$ A teoria sugere que um regime de IT "flexível" pode estabilizar tanto a inflação como a produção. No entanto, não há evidência muito clara de que países emergentes que adotaram o regime de IT obtiveram uma melhor performance em termos de PIB (tanto em termos de crescimento de produção, quanto no coeficiente de variação) quando comparados a países emergentes que não adotaram o regime de IT, conforme apresentados neste artigo. Cabe lembrar que a China, a Índia e a Malásia estão entre os países que apresentaram os maiores índices de crescimento nos últimos anos e não são países que adotaram o regime de IT (seus crescimentos médios foram de 9,9\%, de 6,5\% e de 5,9\%, respectivamente, entre 1993 e 2005). Conseqüentemente, não há evidências de que o regime de IT melhora a performance dos países emergentes, tendo como base os indicadores de inflação e de produção. Esta conclusão sugere que melhores performances não são necessariamente resultantes do regime de IT. $^{22}$

O quadro na América Latina deve ser analisado com atenção, considerando que suas mais importantes economias sofreram crises cambiais recentes: México, em 1994-1995; Brasil, em 1998-1999 e em 2002; e Argentina, em 2001-2002. Essas crises tiveram impactos tanto nas inflações quanto nos PIBs desses países. A Argentina, depois da experiência hiperinflacionária de 19891990, adotou um sistema currency board de câmbio fixo em 1991 e, como resultado, a taxa de inflação declinou abruptamente durante os anos 1990. Em 2002, o país teve uma séria crise monetária e, conseqüentemente, ocorreu uma profunda recessão, 2001-2002, seguida de uma rápida recuperação após a crise. $\mathrm{O}$ México, a despeito do declínio da inflação pós-crise "Tequila", tem tido uma performance econômica pobre nos últimos anos. Embora conclusões gerais sejam difíceis de estabelecer no caso da América Latina devido ao fato de o regime de IT ser recente nesses países, uma observação geral emerge dessa experiência: em dois

(21) Observe que em nossas amostras (Tabela 2, Tabela 3 e Tabela 4), a Venezuela é uma exceção, com uma inflação média de 25,9\% entre 1980 e 1992 e de 37,6\% entre 1993 e 2005. Embora a inflação média na Turquia tenha crescido de 54,6\%, no período 1980-1992, para 59,4\%, no período 1993-2005, a Figura 9 mostra que há uma tendência de ligeira e contínua queda desde 1995.

(22) É importante ressaltar que essa evidência, qual seja, a de que o regime de IT não melhora a performance de inflação e produto dos países emergentes, está relacionada à ocorrência de problemas econômicos específicos inerentes aos países emergentes que não necessariamente se manifestam em países desenvolvidos, o que faz com que o regime de IT nesses últimos países apresente melhores resultados. Entretanto, Ball e Sheridan (2003) mostram que, comparando sete países da OECD que adotaram o regime de IT no início dos anos 1990 com outros 13 países que não o adotaram, na média não há evidência de que IT melhora a performance econômica, tendo como referência a inflação, o produto e a taxa de juros. Os autores concluem que "the formal and institutional aspects of targeting - the public announcements of targets, the inflation reports, the enhanced independence of central banks - are not important. Nothing in the data suggests that convert targets would benefit from adopting explicit targets" (2003, p. 29, grifos adicionados); ver, também, Arestis e Sawyer (2003). 
casos, na Colômbia e no México, a performance econômica piorou desde a adoção de IT, enquanto no Brasil houve uma ligeira melhora (Tabela 2). O Chile é uma exceção, pois tem sido o único país da América Latina a apresentar um crescimento médio do PIB ao redor de 5,0\% ao ano, desde 1990.

Tabela 2

Países emergentes que adotaram o regime de metas de inflação (IT) - \%

\begin{tabular}{l|l|c|c|c|c|c|c|c|c|c|c|c}
\hline \multirow{4}{*}{ País } & \multicolumn{5}{|c|}{ Antes de IT } & \multicolumn{4}{c}{ Depois de IT } \\
\cline { 2 - 11 } & \multicolumn{3}{|c|}{ Inflação } & \multicolumn{3}{c|}{ PIB } & \multicolumn{3}{c}{ Inflação } & \multicolumn{3}{c}{ PIB } \\
\cline { 2 - 10 } & Média & DP & CV & Média & DP & CV & Média & DP & CV & Média & DP & CV \\
\hline
\end{tabular}

América Latina

\begin{tabular}{|l|r|r|l|l|l|l|l|l|l|l|l|l}
\hline Brasil & 9,71 & 9,06 & 0,93 & 2,50 & 1,88 & 0,75 & 8,24 & 2,32 & 0,28 & 2,75 & 1,81 & 0,66 \\
\hline Chile & 20,45 & 5,92 & 0,29 & 3,31 & 6,91 & 2,09 & 7,23 & 5,80 & 0,80 & 5,77 & 3,26 & 0,57 \\
\hline Colômbia & 23,72 & 4,26 & 0,18 & 3,65 & 1,62 & 0,44 & 7,50 & 2,02 & 0,27 & 2,28 & 3,18 & 1,39 \\
\hline México & 20,75 & 9,37 & 0,45 & 3,43 & 3,59 & 1,05 & 7,24 & 4,52 & 0,62 & 2,78 & 2,28 & 0,82 \\
\hline
\end{tabular}

Outros países emergentes

\begin{tabular}{|c|c|c|c|c|c|c|c|c|c|c|c|c|}
\hline Israel & 23,43 & 12,17 & 0,52 & 4,48 & 2,09 & 0,47 & 6,12 & 4,74 & 0,78 & 4,13 & 2,85 & 0,69 \\
\hline Polônia & 29,74 & 11,16 & 0,38 & 7,01 & 5,22 & 0,74 & 5,37 & 4,02 & 0,75 & 3,62 & 1,56 & 0,43 \\
\hline $\begin{array}{c}\text { República } \\
\text { Checa }\end{array}$ & 9,15 & 0,64 & 0,07 & 4,50 & 5,68 & 1,26 & 3,50 & 3,22 & 0,92 & 2,81 & 2,06 & 0,73 \\
\hline Tailândia & 4,98 & 2,06 & 0,41 & 5,28 & 6,55 & 1,24 & 2,16 & 1,51 & 0,70 & 4,93 & 1,67 & 0,34 \\
\hline $\begin{array}{l}\text { Coréia do } \\
\text { Sul }\end{array}$ & 6,19 & 1,71 & 0,28 & 7,73 & 1,91 & 0,25 & 3,41 & 1,94 & 0,57 & 4,21 & 5,04 & 1,20 \\
\hline $\begin{array}{l}\text { África do } \\
\text { Sul }\end{array}$ & 8,03 & 2,61 & 0,32 & 2,22 & 1,92 & 0,87 & 4,95 & 3,35 & 0,68 & 4,18 & 0,94 & 0,23 \\
\hline
\end{tabular}

Nota: Antes de IT / Depois de IT: Brasil: 1995-1998/1999-2005; Colômbia: 1989-1998/19992005; México: 1989-1998/1999-2005; Chile: 1981-1990/1991-2005; República Checa: 19941997/1998-2005 (até 1992, dados da Checoslováquia); Israel: 1986-1991/1992-2005; Polônia: 1992-1997/1998-2005; Tailândia: 1990-1999/2000-2005; Coréia do Sul: 1988-1997/19982005; África do Sul: 1992-2001/2002-2005.

Fonte: IMF/Ipeadata para Brasil/Deutsche Bank Research.

Tabela 3

Países emergentes que não adotaram o regime de metas de inflação (IT) - \%

\begin{tabular}{|c|c|c|c|c|c|c|c|c|c|c|c|c|}
\hline \multirow{3}{*}{ País } & \multicolumn{6}{|c|}{ 1980-1992 } & \multicolumn{6}{|c|}{ 1993-2005 } \\
\hline & \multicolumn{3}{|c|}{ Inflação } & \multicolumn{3}{|c|}{ PIB } & \multicolumn{3}{|c|}{ Inflação } & \multicolumn{3}{|c|}{ PIB } \\
\hline & Média & DP & $\mathrm{CV}$ & Média & DP & $\mathrm{CV}$ & Média & DP & $\mathrm{CV}$ & Média & DP & $\mathrm{CV}$ \\
\hline \multicolumn{13}{|c|}{ América Latina } \\
\hline Argentina & 628,27 & 952,73 & 3,03 & 0,87 & 5,90 & 4,03 & 5,38 & 7,81 & 2,03 & 2,60 & 6,41 & 3,07 \\
\hline Uruguai & 66,06 & 24,96 & 0,38 & 1,86 & 5,33 & 2,87 & 20,16 & 17,06 & 0,85 & 1,96 & 5,92 & 3,02 \\
\hline Venezuela & 25,88 & 20,71 & 0,80 & 1,90 & 5,26 & 2,77 & 37,55 & 24,75 & 0,66 & 0,85 & 7,09 & 8,33 \\
\hline
\end{tabular}


Tabela 3 - Continuação

\begin{tabular}{c|c|c|c|c|c|c|c|c|c|c|c|c|}
\hline \multirow{3}{*}{ País } & \multicolumn{5}{|c|}{$1980-1992$} & \multicolumn{4}{c}{$1993-2005$} \\
\cline { 2 - 11 } & \multicolumn{3}{|c|}{ Inflação } & \multicolumn{3}{c|}{ PIB } & \multicolumn{3}{c|}{ Inflação } & \multicolumn{3}{c}{ PIB } \\
\cline { 2 - 11 } & Média & DP & CV & Média & DP & CV & Média & DP & CV & Média & DP & CV \\
\hline
\end{tabular}

Outros países emergentes

\begin{tabular}{l|r|r|r|r|r|r|r|r|r|r|r|r}
\hline China* & 9,54 & 7,15 & 0,75 & 9,59 & 3,72 & 0,39 & 5,50 & 8,13 & 1,48 & 9,91 & 1,89 & 0,19 \\
\hline Egito ** & 17,22 & 3,87 & 0,23 & 5,08 & 2,13 & 0,42 & 6,39 & 4,26 & 0,67 & 4,58 & 1,33 & 0,29 \\
\hline Índia & 9,72 & 2,55 & 0,26 & 5,35 & 1,83 & 0,34 & 6,52 & 3,18 & 0,49 & 6,46 & 1,52 & 0,24 \\
\hline Malásia & 3,71 & 2,67 & 0,72 & 9,32 & 9,90 & 1,06 & 2,70 & 1,21 & 0,45 & 5,88 & 4,85 & 0,82 \\
\hline Turquia & 54,55 & 22,61 & 0,41 & 4,38 & 3,42 & 0,78 & 59,42 & 30,94 & 0,52 & 4,04 & 5,82 & 1,44 \\
\hline Rússia & n.d. & n.d. & n.d. & n.d. & n.d. & n.d. & 27,11 & 23,26 & 0,86 & 3,95 & 4,95 & 1,25 \\
\hline
\end{tabular}

$\mathrm{DP}=$ desvio-padrão; $\mathrm{CV}=$ coeficiente de variação $(\mathrm{DP} / \mathrm{média})$

Nota: (*) Dados para inflação: 1987-1992 e 1993-2005; (**) Dados para o PIB: 1983-1992 e $1993-$ 2005.

Fonte: IMF / Deutsche Bank Research.

Tabela 4

Países emergentes que adotaram o regime de metas de inflação (período completo) - \%

\begin{tabular}{|c|c|c|c|c|c|c|c|c|c|c|c|c|}
\hline \multirow{3}{*}{ País } & \multicolumn{6}{|c|}{ 1980-1992 } & \multicolumn{6}{|c|}{$1993-2005$} \\
\hline & \multicolumn{3}{|c|}{ Inflação } & \multicolumn{3}{|c|}{ PIB } & \multicolumn{3}{|c|}{ Inflação } & \multicolumn{3}{|c|}{ PIB } \\
\hline & Média & DP & $\mathrm{CV}$ & Média & DP & $\mathrm{CV}$ & Média & DP & $\mathrm{CV}$ & Média & DP & $\mathrm{CV}$ \\
\hline \multicolumn{13}{|c|}{ América Latina } \\
\hline Brasil & 579,24 & 638,69 & 1,10 & 2,03 & 2,03 & 1,00 & 268,47 & 709,48 & 2,64 & 2,95 & 1,89 & 0,64 \\
\hline Chile & 21,29 & 6,76 & 0,32 & 4,70 & 6,62 & 1,41 & 5,47 & 3,56 & 0,65 & 5,10 & 2,83 & 0,55 \\
\hline Colômbia & 24,71 & 4,24 & 0,17 & 3,46 & 1,42 & 0,41 & 13,64 & 7,18 & 0,53 & 2,93 & 2,71 & 0,92 \\
\hline México & 58,10 & 39,54 & 0,68 & 2,73 & 3,68 & 1,35 & & 10,83 & 0,81 & 2,82 & 3,43 & 1,22 \\
\hline \multicolumn{13}{|c|}{ Outros países emergentes } \\
\hline Israel & 103,45 & 116,95 & 1,13 & 3,94 & 1,91 & 0,48 & 5,67 & 4,62 & 0,81 & 3,94 & 2,87 & 0,73 \\
\hline Polônia & 99,90 & 157,53 & 1,58 & $-0,30$ & 6,29 & 21,07 & 13,54 & 12,36 & 0,91 & 5,26 & 3,94 & 0,75 \\
\hline $\begin{array}{c}\text { República } \\
\text { Checa* }\end{array}$ & 7,20 & 15,59 & 2,17 & $\mathrm{n}, \mathrm{a}$, & $\mathrm{n}, \mathrm{a}$, & $\mathrm{n}, \mathrm{a}$, & 5,38 & 3,80 & 0,71 & 3,37 & 3,49 & 1,04 \\
\hline Tailândia & 5,68 & 5,12 & 0,90 & 7,72 & 2,99 & 0,39 & 3,62 & 2,39 & 0,66 & 4,22 & 5,27 & 1,25 \\
\hline $\begin{array}{l}\text { Coréia do } \\
\text { Sul }\end{array}$ & 8,33 & 7,92 & 0,95 & 7,79 & 3,36 & 0,43 & 4,01 & 1,74 & 0,43 & 5,32 & 4,25 & 0,80 \\
\hline $\begin{array}{l}\text { África do } \\
\text { Sul }\end{array}$ & 14,58 & 1,88 & 0,13 & 1,45 & 3,02 & 2,08 & 6,63 & 2,47 & 0,37 & 3,16 & 1,32 & 0,42 \\
\hline
\end{tabular}

Nota: (*) Dados da Checoslováquia para 1980-1993.

Fonte: IMF/Ipeadata para Brasil/Deutsche Bank Research.

\subsection{A performance da inflação e do PIB no Brasil}

Embora seja observada uma visível tendência de queda da inflação nos países emergentes, o Brasil é um caso interessante. A inflação manteve-se alta em relação à de outros países de regime de IT durante o mesmo período, mas o 
coeficiente de variação foi um dos mais baixos (Tabela 2). Ademais, a performance do PIB brasileiro tem sido fraca. Quando se considera o período de implementação de IT (1999 a 2005), a taxa média de crescimento foi da ordem de 2,6\% ao ano. Se não bastasse esse baixo crescimento, o PIB brasileiro tem seguido um padrão à la stop-and-go durante esse período.

Durante o regime de IT, a taxa de juros tem sido muito alta. Entre 1999 e 2005, a taxa média de juros, Selic, foi da ordem de 19,6\% (Figura 1), enquanto a taxa de juros real, deflacionada pelo IPCA, apresentou uma média anual de 10,5\%. Esta tem sido elevada devido à rigidez da política monetária, que é focada na manutenção, a qualquer custo, do controle da inflação, na redução da dívida pública e na estabilização da volatilidade da taxa cambial. Estudos empíricos mostram que as Autoridades Monetárias utilizam as taxas de juros não só para controlar a inflação diretamente, mas, também, para influenciar a taxa câmbio, tentando controlar as pressões sobre esta, evidenciando um comportamento do tipo "fear of floating". ${ }^{23}$ As conseqüências de taxas de juros elevadas são por demais conhecidas: (i) sérias restrições ao crescimento econômico, visto que o custo do crédito encarece, afetando, assim, as expectativas de investimento dos empresários; e (ii) o aumento da dívida pública, que é constituída principalmente por títulos públicos indexados à taxa Selic. ${ }^{24}$ Apesar da melhora do balanço de pagamentos desde 2003, devido principalmente ao crescente superávit comercial, a experiência recente do Brasil mostra que em países com um alto nível de dívida externa e com uma conta de capital totalmente liberalizada, as flutuações de capital externo podem causar períodos de instabilidade cambial intensa. Isso, por sua vez, pode prejudicar os esforços para alcançar e manter as metas de inflação anunciadas. Essa situação tem causado, também, um baixo crescimento econômico, pois as Autoridades Monetárias tendem a aumentar as taxas de juros nos períodos de turbulência externa, a fim de atingir as metas preestabelecidas e estabilizar a taxa de câmbio. Por outro lado, durante o "período de tranquiilidade", em que os países apresentam maciças entradas de capitais, as taxas de juros são utilizadas com a finalidade de atrair capitais, o que acaba apreciando a taxa de câmbio e contribuindo para trazer a inflação para as suas metas.

(23) Mendonça (2005), utilizando regras de Taylor, realiza um estudo para determinar a taxa de juros do BCB no período 1999-2004. Uma das conclusões é a de que variações na taxa de câmbio explicam as significativas variações na taxa de juros básica Selic (cerca de $57 \%$ depois de um ano do choque cambial de 2003).

(24) O comportamento da dívida pública doméstica no Brasil tem mostrado ser particularmente vulnerável a mudanças na taxa de juros e na taxa de câmbio (veja, por exemplo, Paula; Alves Jr., 2003). 
Figura 1

Taxa média da Selic (\%), 1999-2005

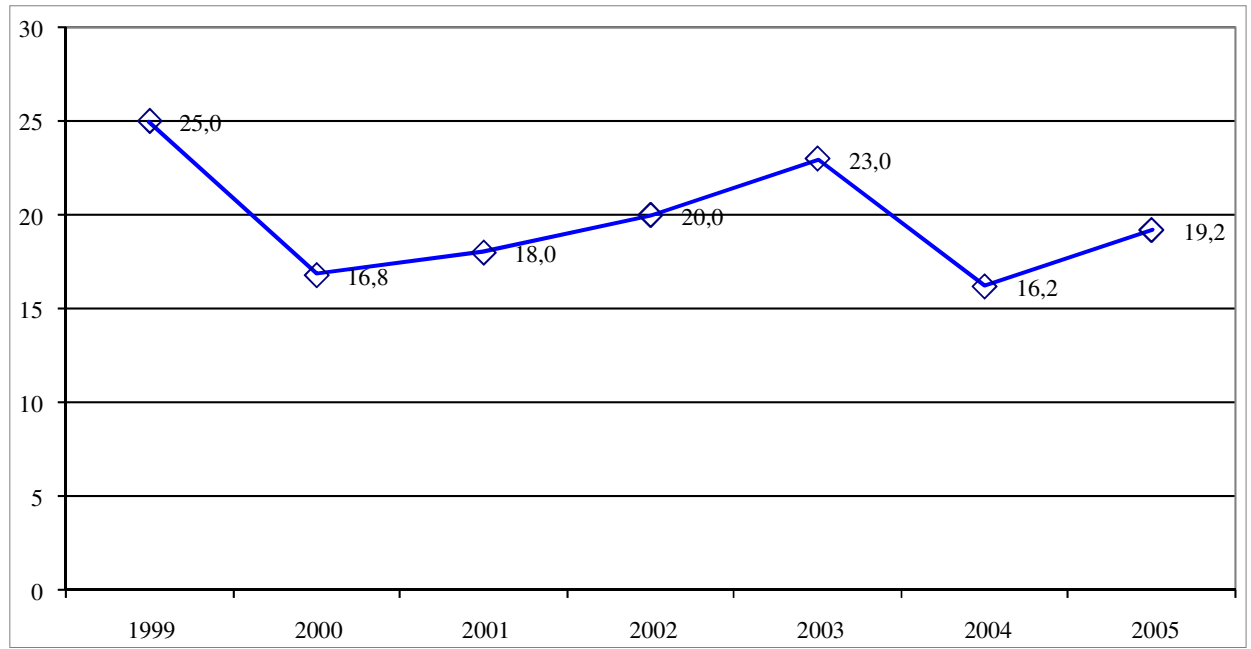

Fonte: BCB.

No Brasil, a volatilidade da taxa de câmbio tem sido considerável ${ }^{25}$ (Figura 2). Como foi discutido anteriormente, a instabilidade macroeconômica ocasionou uma forte desvalorização do real, que, como resultado, afetou os preços domésticos (efeito pass-through). Isso ocorreu devido tanto ao impacto direto da desvalorização sobre os produtos importados quanto, indiretamente, através dos preços administrados, que são relativamente insensíveis à demanda doméstica e às condições de oferta ou são regulados por agências reguladoras. O grupo inclui, por exemplo, produtos à base de petróleo e tarifas telefônicas, de eletricidade residencial e de transporte público. Sua dinâmica difere-se da do grupo de preço de mercado em três aspectos: " $i$ ) dependence on international prices in the case of oil by-products; ii) greater pass-through from the exchange rate $;^{26}$ and iii) stronger backward-looking behavior" (Minella et al., 2003, p. 7), já que as tarifas de eletricidade e telefônicas são geralmente ajustadas anualmente pelo Índice

(25) Souza e Hoff (2006), utilizando os indicadores de fear of floating de Calvo e Reihart, mostram que, de janeiro de 1999 a dezembro de 2005, a freqüência em que a variação mensal da taxa de câmbio excedeu a banda de $+/-2,5 \%$ foi de $52 \%$ no Brasil, ao passo que em outros países emergentes da América Latina ela foi de $27 \%$ e em alguns países asiáticos (Indonésia, Cingapura, Tailândia e Coréia do Sul), ela foi de 19\%.

(26) De acordo com Minella et al. (2003, p. 7) "It]here are three basic links: i) the price of oil byproducts for consumption depends on international oil prices denominated in domestic currency; ii) part of the resetting of electricity rates is linked to changes in the exchange rate; and iii) the contracts for price adjustments for electricity and telephone rates link these adjustments, at least partially, to the General Price Index (IGP), which is more affected by the exchange rate than the consumer price indexes". 
Geral de Preços (IGP). ${ }^{27}$ Nossas estimativas indicam que os preços administrados representaram cerca de $28 \%$ do IPCA, entre abril de 2003 e dezembro de 2005 (Figura 3). Além disso, a Figura 4 mostra que os preços administrados cresceram mais do que os preços de mercado. De fato, enquanto a taxa de inflação acumulada relacionada aos preços de mercado estava em 57\%, no período 1999-2005, os preços administrados variaram $137 \%$, ou seja, um aumento de mais de $50 \%$ em relação aos preços de mercado. ${ }^{28}$ Os preços administrados no Brasil são estabelecidos por contratos baseados nas variações anteriores do índice de preço. É por essa razão que algum grau de persistência é evidente na formação dos índices de preços, incluindo o IPCA.

Figura 2

Brasil - Volatilidade da taxa de câmbio

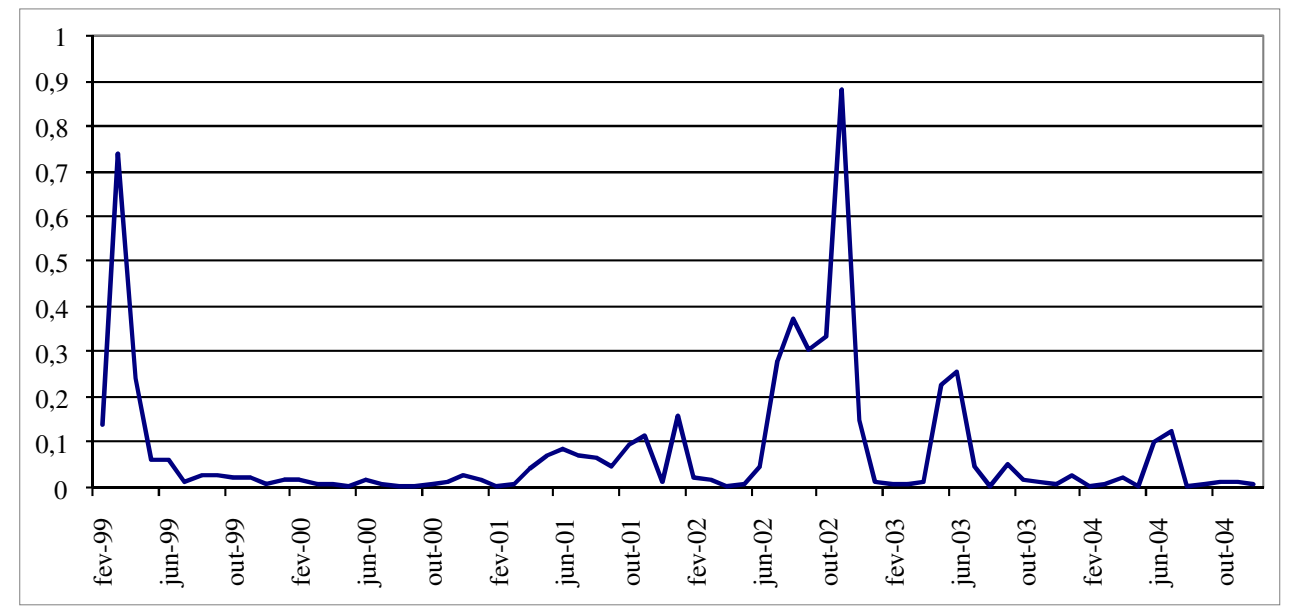

Nota: A volatilidade da taxa de câmbio é calculada utilizando-se um modelo GARCH (Generalised Autoregressive Conditional Heteroskedastic), isto é, um modelo não-linear usado para calcular a volatilidade de séries temporais.

Fonte: Cálculos dos autores baseados em dados do BCB.

(27) Como se sabe, o IGP é calculado pela Fundação Getúlio Vargas (FGV), sendo um índice ponderado que inclui o índice de preços por atacado - IPA (60\%); índice do preço ao consumidor - IPC (30\%); e índice nacional de custos da construção - INCC (10\%). A razão para o uso desse índice para ajustar as tarifas de eletricidade e telefonia (em vez do IPCA) é que esses serviços foram privatizados na segunda metade dos anos 1990, quando o governo brasileiro estava interessado em atrair empresas estrangeiras e para essas firmas o IGP é melhor do que o IPCA, uma vez que é mais sensível às variações na taxa de câmbio (devido ao elevado peso do IPA).

(28) O IPCA, de 1999 a 2005, acumulou uma variação de 73,9\%. 
Figura 3

Brasil: percentagem dos preços administrados sobre IPCA

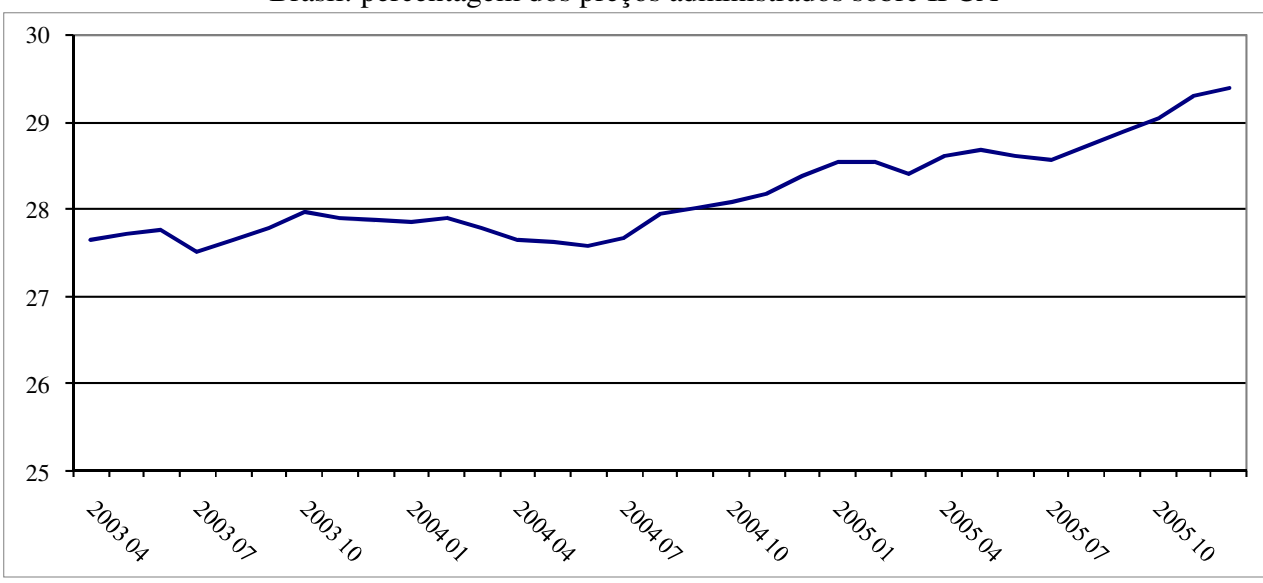

Nota: Preços administrados incluem serviços de utilidades (tarifas de telefones e de eletricidade residencial, entre outros), produtos derivados do petróleo, planos privados de saúde, etc.; isto é, são preços determinados ou autorizados pelo governo.

Fonte: Cálculos dos autores baseados em informações do IBGE.

Figura 4

Brasil: preços livres e preços administrados no IPCA

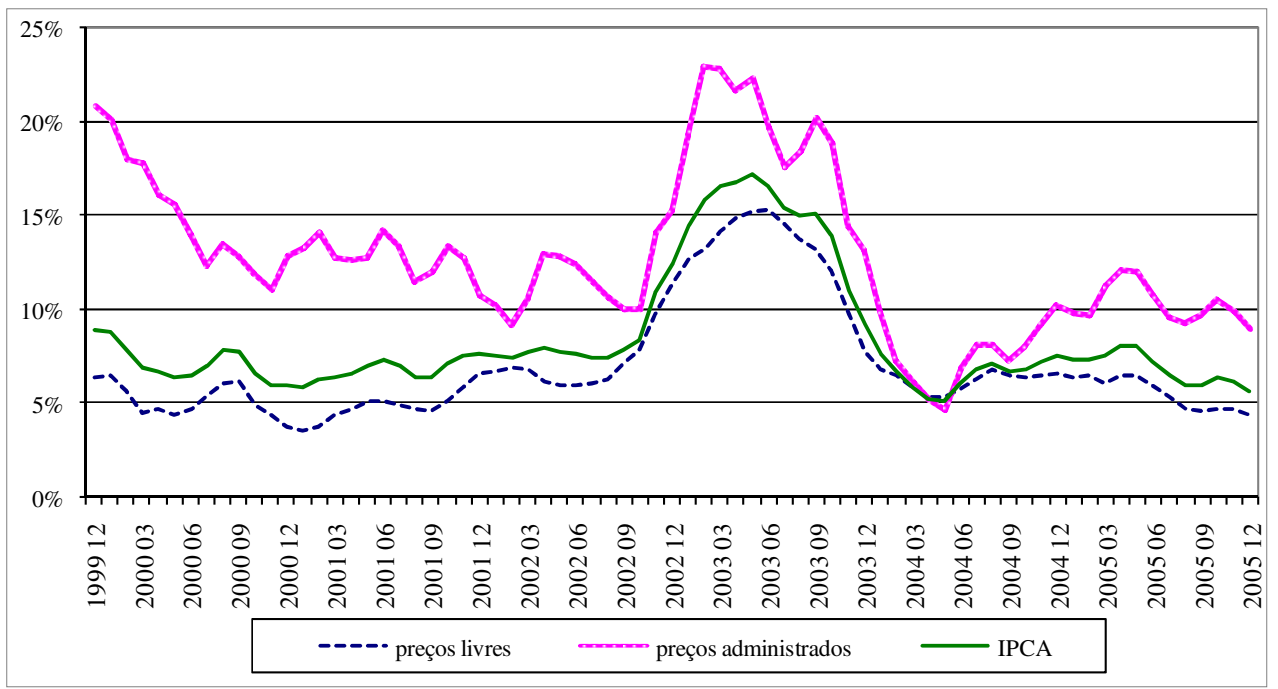

Fonte: Ipeadata.

Um comentário final sobre o mecanismo de transmissão da taxa de câmbio para a inflação é necessário. As variações na taxa de câmbio afetam o IGP, que, por sua vez, afeta o índice de preços 
administrados. Como os preços administrados mudam, ${ }^{29}$ o IPCA também é alterado. Essa variação é também devida às alterações na taxa de câmbio por causa do impacto sobre insumos importados. Como o IGP tem sido maior do que o IPCA, este tem sido influenciado pelo comportamento do IGP através do ajustamento dos preços administrados (Figura 5). ${ }^{30}$

Figuras 5

Brasil: desvio da taxa de câmbio e taxas de inflação

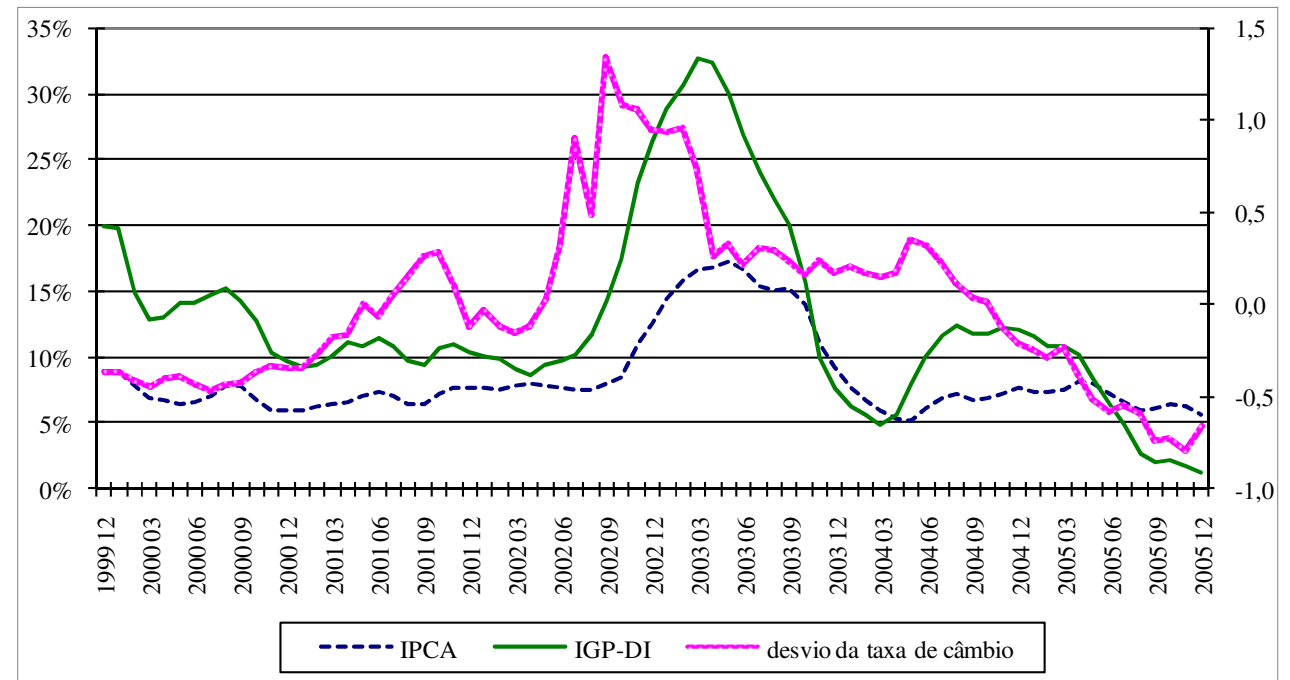

Fonte: Ipeadata.

Nota: Ver as notas de rodapé de números 13 e 27 para maiores detalhes sobre o IPCA e o IGP, respectivamente. $\mathrm{O}$ desvio da taxa de câmbio foi calculado pela diferença entre a taxa nominal de câmbio e a sua tendência linear.

Desse modo, períodos de depreciação cambial prolongada resultam em elevação da taxa de inflação; por outro lado, períodos de apreciação cambial - como a ocorrida recentemente - resultam em redução da taxa de inflação, após um intervalo de tempo. Como demonstramos na Seção 3.2, o declínio da taxa de inflação em 2005, comparativamente a 2003 e 2004, está basicamente relacionado à apreciação cambial durante aquele ano. Logo, a inflação no Brasil é muito

(29) Minella et al. (2003, p. 25) estimaram que o efeito pass-through para os preços administrados, entre julho de 1997 e dezembro de 2002, foi de 25,0\%, resultando em um efeito pass-through de aproximadamente $16 \%$ para o IPCA.

(30) Figueiredo e Ferreira (2002), utilizando uma análise de regressão simples, mostram que o índice geral de preços e o índice de preços de oferta doméstica são fundamentais para explicar as diferenças entre os preços de mercado e os preços administrados. 
influenciada pelos movimentos da taxa de câmbio. ${ }^{31}$ Sob essas condições, a política monetária pode ter efeito sobre determinados preços de mercado, mas, todavia, não é muito eficiente no controle dos preços administrados. Considerando a importância dos preços administrados na determinação da taxa de inflação brasileira, as pressões inflacionárias acabam resultando no aumento mais do que o necessário das taxas de juros, por parte do $\mathrm{BCB}$, para restringir a inflação gerada pelos preços de mercado. Isso ocorre porque o $\mathrm{BCB}$ deve considerar os choques secundários que emanam dos choques dos preços administrados. ${ }^{32}$

Além disso, o Brasil é o único país no mundo onde o banco central determina diretamente as taxas de juros que remuneram a dívida pública e essas são usadas também como meta operacional de política monetária, determinando o custo das reservas bancárias. Essa situação anômala constitui uma herança da era da alta inflação que ainda permanece intacta. De fato, como cerca de $40 \%$ dos títulos federais são indexados à taxa overnight (Selic) e eles são utilizados pelos bancos na composição dos fundos de renda fixa, logo qualquer aumento nas taxas de juros resulta em um aumento imediato do estoque total da dívida pública. ${ }^{33}$ Ocorre que, assim, uma elevação da taxa de juros por parte do BCB, como ocorreu a partir de meados de 2004, é seguida, ceteris paribus, por um aumento nas condições de liquidez da economia, medido pela variação dos agregados monetários, tais como M3 e M4 (Figura 6). Isso pode, também, causar um maior nível de gastos de consumo por parte das empresas e das famílias, visto que o aumento da remuneração dos fundos de renda fixa gera um efeito de riqueza positivo sobre o consumo. Esse aumento nos gastos, por sua vez, sobrepõe-se ao impacto negativo no consumo que resulta de maiores taxas de juros (Nakano, 2005). Há duas consequiências desse modus operandi da política monetária brasileira. Primeiro, de modo a ter impacto sobre a demanda, o BCB precisa elevar a taxa de juros suficientemente para que os bancos sejam forçados a racionar o crédito devido ao aumento do risco de inadimplência. Segundo, o aumento das taxas de juros, em um contexto de arbitragem entre as taxas domésticas e externas,

(31) Ferreira (2004), utilizando um modelo VAR para analisar os determinantes da taxa de inflação no Brasil para o período 1995-2004, encontra uma resposta positiva da inflação a choques nominais de taxa de câmbio, com um efeito prolongado ao longo do tempo. Na mesma direção, Gomes e Aidar (2005) estimam, utilizando também um modelo VAR, a regra de Taylor para a economia brasileira, para o período janeiro de 1999 a maio de 2004 , e concluem que $24,4 \%$ da taxa de inflação (IPCA) são explicados pela variação da taxa de câmbio. É interessante notar que alguns economistas do BCB, também, concluem que "exchange rate volatility is an important source of inflation variability. The design of the inflation-targeting framework has to take into account this issue to avoid that a possible non-fulfillment of inflation targets as a result of exchange rate volatility may reduce the credibility of the central bank" (Minella et al., 2003, p. 29).

(32) Cabe ressaltar que o canal do crédito é, também, limitado no Brasil, visto que a razão crédito/PIB variou, conforme dados do BCB, de $24 \%$ a $30 \%$, entre 2000 e 2005, enquanto essa razão para países emergentes foi de, na média, $89 \%$ no período 1999-2002 (IADB, 2005, p. 7).

(33) Conforme os dados do Ipeadata, a razão dívida líquida do setor público/PIB cresceu de 34,4\% em 1997 para $52,6 \%$ em 2001. 
causa uma apreciação cambial. Isso funciona como um choque positivo no lado da oferta da economia, pois reduz os custos das matérias-primas importadas e dos preços dos bens comercializáveis no mercado doméstico. Conseqüentemente, devido ao efeito transmissor da taxa de câmbio, a política monetária é o instrumento mais eficiente em países como o Brasil.

Em suma, a inflação no Brasil tem sido basicamente de custos e explicada principalmente por choques de oferta, negativos ou positivos (movimentos na taxa de câmbio, mudanças nos preços internacionais de commodities e de energia, etc.), e por uma inércia parcial causada pela indexação dos preços administrados.

Figura 6

Agregados monetários do Brasil

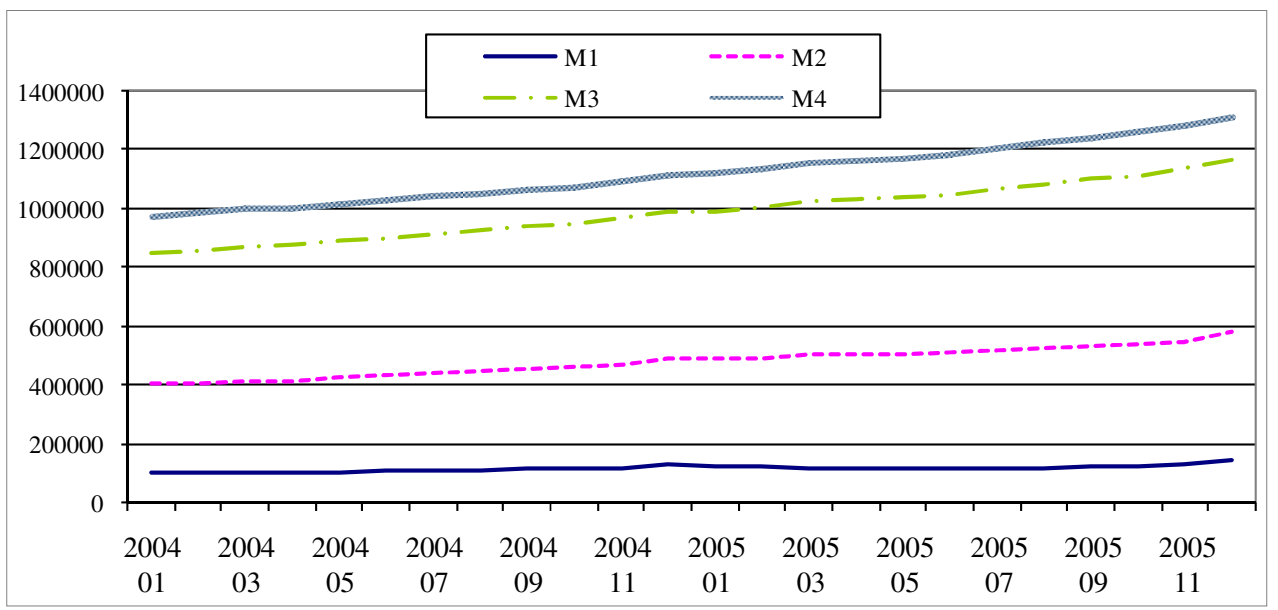

Nota: (1) M1 = moeda em poder do público + depósitos à vista; M2 = M1 + poupança + títulos emitidos por instituições financeiras; $\mathrm{M} 3=\mathrm{M} 2+$ fundos de renda fixa + operações de títulos públicos federais; M4 = M3 + títulos da dívida pública (indexados à Selic) + títulos estaduais e municipais. (2) R \$ milhões.

Fonte: BCB.

\section{Sumário e conclusões}

Neste artigo, apresentamos os aspectos teórico-operacionais do regime de IT e, também, os princípios que sinalizaram a implementação do referido regime no Brasil. Fica claro nessa análise que as Autoridades Monetárias brasileiras aderem religiosamente aos princípios teóricos da estrutura do regime de IT.

Ao examinamos a experiência do Brasil com o regime de IT, comparandoa com a experiência de outros países que, na mesma época, adotaram ou não adotaram o regime de IT, algumas conclusões gerais emergem dessa análise. Os países que adotaram IT parecem ter sido bem-sucedidos em controlar a inflação; porém, os países que não adotaram o regime de IT parecem ter vivenciado o mesmo. Além disso, embora o Brasil tenha implementado o regime de IT em 
conformidade com as regras de Taylor, a inflação ainda é ligeiramente elevada: a inflação média, entre 1999 e 2005, foi da ordem de 8,2\% ao ano. O interessante é que, a despeito de o Brasil, ao longo desse período, ter tido uma das maiores taxas de juros do mundo, a inflação média ainda é elevada. Nesse sentido, o BCB tem mantido as taxas de juros elevadas para que a inflação convirja para o centro da meta preestabelecida. Por sua vez, elevadas taxas de juros têm contribuído para o baixo crescimento econômico e para a deterioração de outras variáveis macroeconômicas, tais como a dívida pública. Parece, assim, que o atual quadro de juros elevados e câmbio valorizado, por mais que sejam imprescindíveis para estabilizar o processo inflacionário, não tem sido dos mais promissores para a economia brasileira, pois o crescimento econômico tem sido baixo e a inflação, apesar de declinante, ainda é relativamente alta.

Nossos resultados estão de acordo com as recentes contribuições de autores que analisam o regime de IT para vários países da América Latina, especialmente com a argumentação de Eichengreen (2002) na qual o regime de IT é mais emblemático para os países latino-americanos por três razões específicas: suas economias estão expostas a choques financeiros e de commodities internacionais causados pela liberalização das contas comercial e de capitais do balanço de pagamentos; suas dívidas estão predominantemente dolarizadas; e as autoridades políticas não possuem credibilidade. As duas primeiras razões são pertinentes a alguns países da América Latina. A abertura econômica expõe essas economias a distúrbios decorrentes de flutuações cambiais que acabam causando inflação via efeito pass-through. A dolarização da dívida afeta as instituições financeiras porque, em termos gerais, o sistema bancário dos países latinoamericanos é fraco e, como tal, está sujeito a vulnerabilidade financeira quando da ocorrência de choques externos. Entretanto, Paula e Alves Jr. (2003) demonstram que essas não são as consequiências típicas do sistema bancário brasileiro nos últimos anos. Além disso, o regime de IT é bastante rígido para esses países, principalmente porque ele afeta o crescimento econômico e a flexibilidade da taxa de câmbio requerida para esse tipo de regime monetário. A flexibilidade da taxa de câmbio, por conseguinte, pode causar instabilidade financeira, o que é uma possibilidade bastante provável nesses países, como a história recente demonstrou. Schmidt-Hebel e Werner (2002, p. 2) são muito claros ao sinalizar os problemas que o regime de IT pode representar: "All Latin American inflation targeters are open economies that employ floating exchange rate regimes ... [and] are subject to large external shocks and significant exchange rate volatility, and the exchange rate may therefore play an important role in the conduct of monetary policy under inflation targeting". A volatilidade da taxa de câmbio gera freqüentes mudanças nas taxas de inflação, que acabam mostrando a incapacidade dos países que adotam o regime de IT de atingir metas preestabelecidas. 
Os choques externos manifestados nos países da América Latina nos anos 1990 afetaram a taxa de câmbio e, conseqüentemente, a taxa de inflação, o que fez com que as taxas de juros se elevassem para enfrentar as pressões inflacionárias. Como resultado, essas economias foram geralmente confrontadas por altas volatilidades das taxas de juros e de câmbio. Nesse contexto, "monetary policy in emerging economies may therefore be more sensitive to exchange rate movements both indirectly (because of pass-through effects on inflation) and directly (because the exchange rate is an additional argument in central bank objective functions, reflecting their concern for devaluation-induced bank failures and domestic recessions)" (Schmidt-Hebel; Werner, 2002, p. 15). Em outras palavras, o efeito pass-through decorrente de variações cambiais para a inflação é maior e mais significante nas economias latino-americanas do que em países desenvolvidos, pois nos primeiros há um grau de abertura econômica maior, um histórico de alta inflação e uma baixa credibilidade dos bancos centrais. Ademais, os países da América Latina apresentam grandes descasamentos entre ativos e obrigações em moeda estrangeira, o que acaba gerando comportamentos dos agentes econômicos à la self-fulfilling e, por conseguinte, crises financeiras que afetam os ativos dos países e provocam recessão. Esse é o caso em que os países latino-americanos são mais suscetíveis a choques de oferta - talvez mais do que muitos outros países. Generalizando a análise, o regime de IT pode não funcionar de forma efetiva naqueles países onde choques de oferta predominam sobre choques de demanda.

\section{Bibliografia}

ARESTIS, P.; SAWYER, M. Inflation targeting: a critical appraisal. Levy Economics Institute Working Paper, n. 388, Sept. 2003.

; PAULA, L. F.; FERRARI-FILHO, F. Inflation targeting in emerging countries: the case of Brazil. In: ARESTIS, P.; SAAD-FILHO, A. (Ed.). Political economy of Latin America: recent economic performance. Basingstoke: Palgrave Macmillan, 2007a.

Assessing the economic policies of President Lula da Silva in Brazil: has fear defeated hope? In: ARESTIS, P.; SAAD-FILHO, A. (Ed.). Political economy of Latin America: recent economic performance. Basingstoke: Palgrave Macmillan, 2007b.

BALL, L.; SHERIDAN, N. Does inflation targeting matter? NBER Working Paper Series, n. 9577, p. 1-47, 2003.

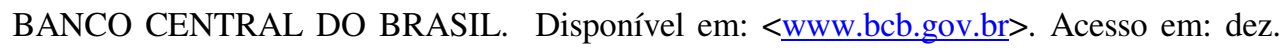
2006.

BARBOSA-FILHO, N. Inflation targeting in Brazil: 1999-2006. 2007. Disponível em: $<$ www.networkideas.org/feathm/oct2007/pdf/Barbosa.pdf $>$.

BARRO, R. J.; GORDON, D. B. A positive theory of monetary policy in a natural rate model. Journal of Political Economy, v. 91, n. 3, p. 589-619, 1983. 
BERNANKE, B. S.; GERTLER, M. Monetary policy and asset price volatility. In: New Challenges for Monetary Policy, Proceedings of the Symposium Sponsored by the Federal Reserve Bank of Kansas City, Jackson Hole, Wyoming, Aug. 26-28, 1999.

; GILCHRIST, S. The financial accelerator in a quantitative business cycle framework. In: TAYLOR, J.; WOODFORD, M. (Ed.). Handbook of macroeconomics. Amsterdam: North Holland, 1999. v. 1.

; MISHKIN, F. S. Inflation targeting: a new framework for monetary policy? Journal of Economic Perspectives, v. 11, n. 2, p. 97-116, 1997.

BOGDANSKI, J.; TOMBINI, A. A.; WERLANG, S. R. Implementing inflation targeting in Brazil. Brasília, DF: Banco Central do Brasil, jul. 2000. p. 1-29, 2000. (Working Papers Series).

CALVO, G. On the time consistency of optimal policy in the monetary economy. Econometrica, v. 46, n. 4, p. 1411-1428, 1978.

CLARIDA, R.; GALÍ, J.; GERTLER, M. Monetary policy rules and macroeconomic stability: evidence and some theory. Quarterly Journal of Economics, v. 115, n. 1, p. 147$180,2000$.

DEBELLE, G.; FISCHER, S. How independent should a Central Bank be? In: FUHRER, J. C. (Ed.). Goals, guidelines, and constraints facing monetary policymakers. Boston: Federal Reserve Bank of Boston, 1994.

DE FIORE, F.; LIU, Z. Openness and equilibrium determinacy under interest rate rules. Frankfurt: European Central Bank, 2002. (Working Paper, n. 173).

DEUTSCHE BANK RESEARCH. Disponível em: <www.dbresearch.de $>$. Acesso em: dez. 2006.

EICHENGREEN, B. Can emerging markets float? Should they inflation target? Brasília, DF: Banco Central do Brasil, fev. 2002. p. 1-46, 2002. (Working Papers Series).

FERRARI-FILHO, F.; PAULA, L.F. The legacy of the Real Plan and an alternative agenda for the Brazilian economy. Investigación Económica, 244, p. 57-92, 2003.

FERREIRA, A. B. Metas para a inflação e vulnerabilidade externa: um estudo do Brasil. Dissertação (Mestrado)-CEDEPLAR/UFMG, Belo Horizonte, 2004.

FIGUEIREDO, F. M.; FERREIRA, T.P. Os preços administrados e a inflação no Brasil. Brasília, DF: Banco Central do Brasil, dez. 2002. p. 1-32. (Working Papers Series).

FISCHER, S. Modern Central Banking. In: CAPIE, F.; GOODHART, C.; FISCHER, S.; SCHNADT, N. (Ed.). The future of Central Banking. Cambridge: Cambridge University Press, 1994.

GARFINKEL, M. R.; OH, S. Strategic discipline in monetary policy with private information: optimal targeting horizons. American Economic Review, v. 83, n. 1, p. 99$117,1993$.

GOMES, C.; AIDAR, O. Metas inflacionárias, preços livres e administrados no Brasil. In: ENCONTRO NACIONAL DE ECONOMIA POLÍTICA, 10, Campinas, 2005. Anais... 
IADB - INTER-AMERICAN DEVELOPMENT BANK. Unlocking credit: the quest for deep and stable bank lending. Washington: IADB, 2005.

IBGE - INSTITUTO BRASILEIRO DE GEOGRAFIA E ESTATÍSTICA.. Disponível em: <www.ibge.gov.br>. Acesso em: dez. 2006.

IMF - INTERNATIONAL MONETARY FUND. International Financial Statistics Yearbook. Washington: IMF, 2007.

IPEADATA. Disponível em: <www.ipeadata.gov.br>. Acesso em: dez. 2006.

JOHNSON, D. R. The effect of inflation targets on the level of expected inflation in five countries. Review of Economics and Statistics, v. 85, n. 4, p. 1076-1081, 2003.

KING, M. The inflation target ten years on. Bank of England Quarterly Bulletin, Summer, v. 42, n. 4, p. 459-474, 2002.

KREGEL, J. Was there an alternative to the Brazilian crisis? Revista de Economia Política, v. 19, n. 3, p. 23-38, 1999.

KYDLAND, F.; PRESCOTT, E. C. Rules rather than discretion: the inconsistency of optimal plans. Journal of Political Economy, v. 85, n. 3, p. 473-492, 1977.

MENDONÇA, H. O efeito dos preços administrados na taxa de juros brasileira. In: ENCONTRO NACIONAL DE ECONOMIA POLÍTICA, 10, Campinas, 2005. Anais...

MINELlA, A.; FREITAS, P.; GOLDFAJN, I.; MUINHOS, M. Inflation targeting in Brazil: constructing credibility under exchange rate volatility. Brasília, DF: Banco Central do Brasil, nov. 2003. p. 1-32. (Working Papers Series, n. 77).

MISHKIN, F. S. What should Central Banks do? Federal Reserve Bank of St. Louis Review, v. 82, n. 6, p. 1-13, 2000.

NAKANO, Y. O regime monetário e de dívida pública brasileira e a alta taxa de juros. Revista de Conjuntura Econômica, v. 59, n. 11, p. 10-12, 2005.

PAULA, L. F.; ALVES JR., A. J. Banking behaviour and the Brazilian economy after the Real Plan: a post-Keynesian approach. BNL Quarterly Review, 227, p. 337-365, 2003.

SCHMIDT-HEBEL, K.; WERNER, A. Inflation targeting in Brazil, Chile, and Mexico: performance, credibility, and the exchange rate. Santiago de Chile: Banco Central de Chile, 2002. (Documentos de Trabajo, n. 171).

SOUZA, F. E.; HOFF, C. O regime cambial brasileiro: 7 anos de flutuação. 2006. Disponível em: $\leq$ http://www.ie.ufrj.br/conjuntura/pdfs/TextoRedeMercosul.pdf $>$.

STERNE, G. Inflation targets in a global context. In: LOAYZA, N.; SOTO, R. (Ed.). Inflation targeting: design, performance, challenges. Chile: Central Bank of Chile, 2002.

SVENSSON, L. E. O. Commentary on Meyer: practical problems and obstacles to inflation targeting. Federal Reserve Bank of St. Louis Review, v. 86, n. 4, p. 161-164, 2004.

TAYLOR, J. B. Discretion versus policy rules in practice. Carnegie-Rochester Conference Series on Public Policy, p. 195-214, Dec. 1993. 


\section{Anexo}

Figura 7

Países latino-americanos

(a) Países latino-americanos que adotaram o regime de IT
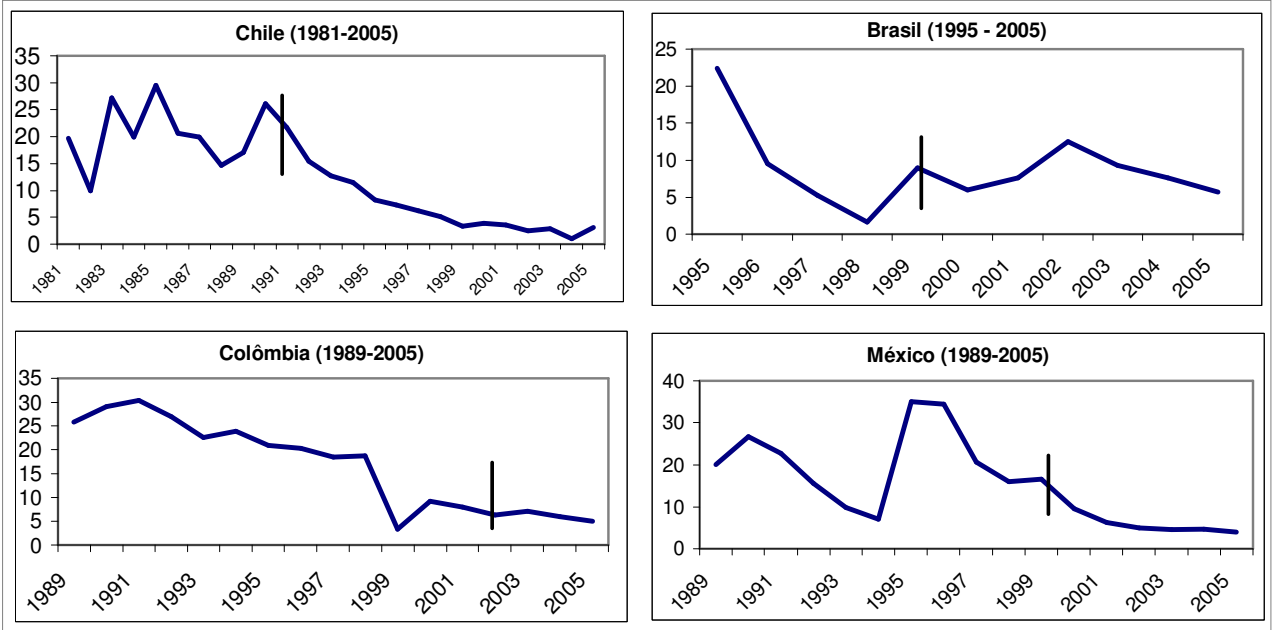

(b) Países latino-americanos que não adotaram o regime de IT
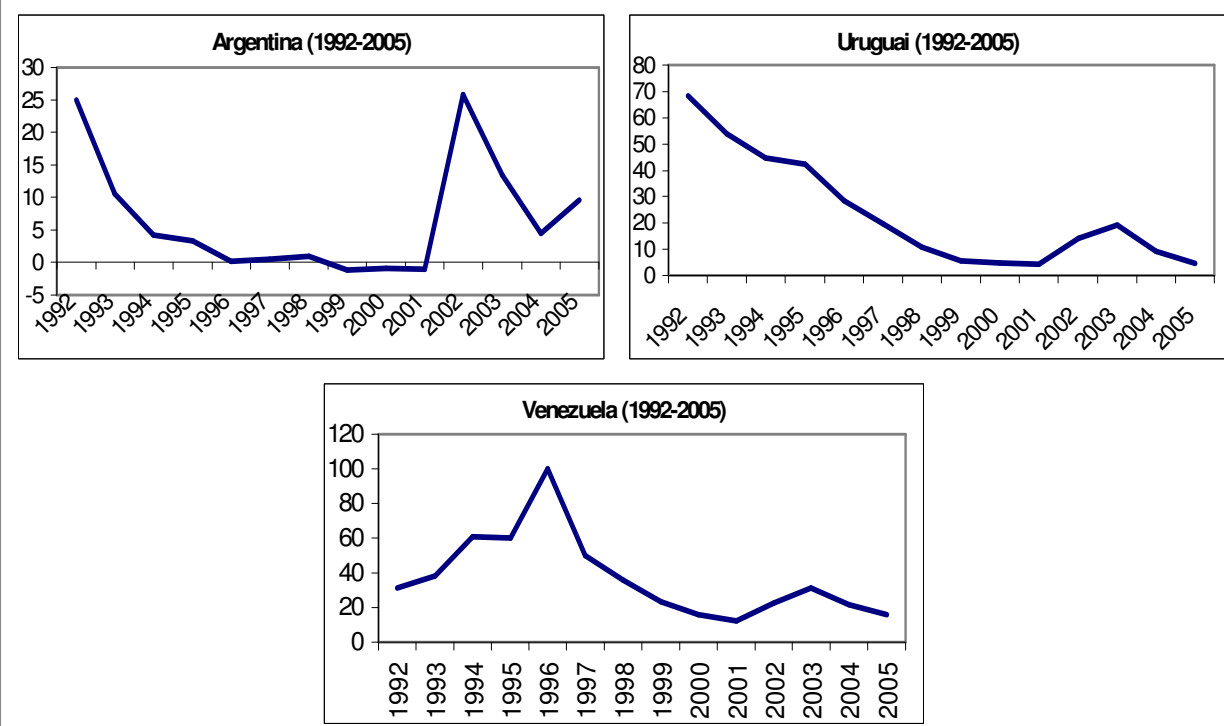

Fonte: IMF e Ipeadata para o Brasil. 
Figura 8

Outros países emergentes que adotaram o regime de IT
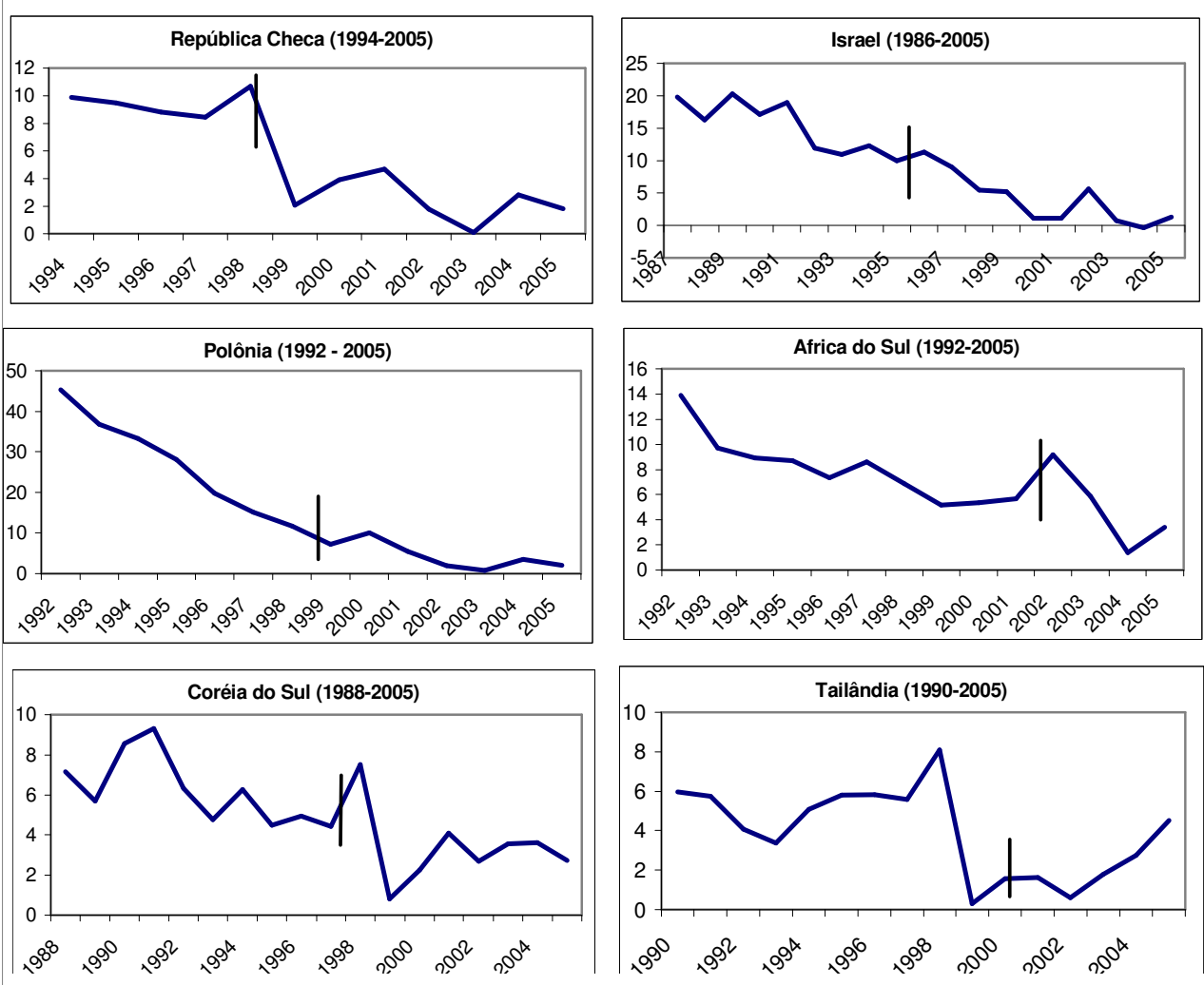

Fonte: IMF. 
Figura 9

Outros países emergentes que não adotaram o regime de IT
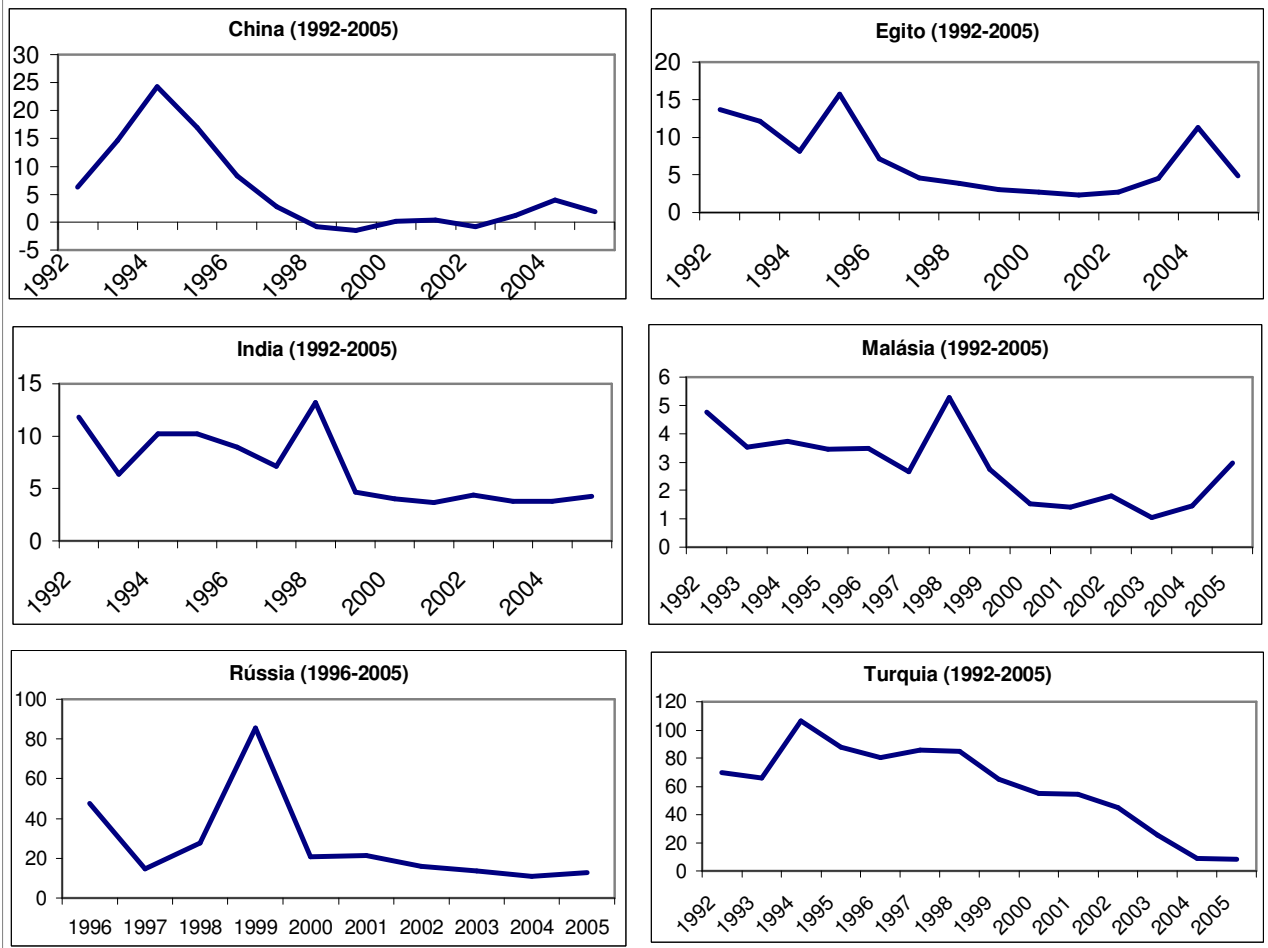

Fonte: IMF. 